The University of Southern Mississippi

The Aquila Digital Community

Master's Theses

Summer 2012

\title{
The Effects of the Good Behavior Game With General Education High School Students
}

Rachel R. Mitchell

University of Southern Mississippi

Follow this and additional works at: https://aquila.usm.edu/masters_theses

Part of the Psychology Commons

\section{Recommended Citation}

Mitchell, Rachel R., "The Effects of the Good Behavior Game With General Education High School Students" (2012). Master's Theses. 447.

https://aquila.usm.edu/masters_theses/447

This Masters Thesis is brought to you for free and open access by The Aquila Digital Community. It has been accepted for inclusion in Master's Theses by an authorized administrator of The Aquila Digital Community. For more information, please contact Joshua.Cromwell@usm.edu. 
The University of Southern Mississippi

THE EFFECTS OF THE GOOD BEHAVIOR GAME WITH

GENERAL EDUCATION HIGH SCHOOL STUDENTS

by

Rachel Ritter Mitchell

A Thesis

Submitted to the Graduate School

of The University of Southern Mississippi

in Partial Fulfillment of the Requirements

for the Degree of Master of Arts

Approved:

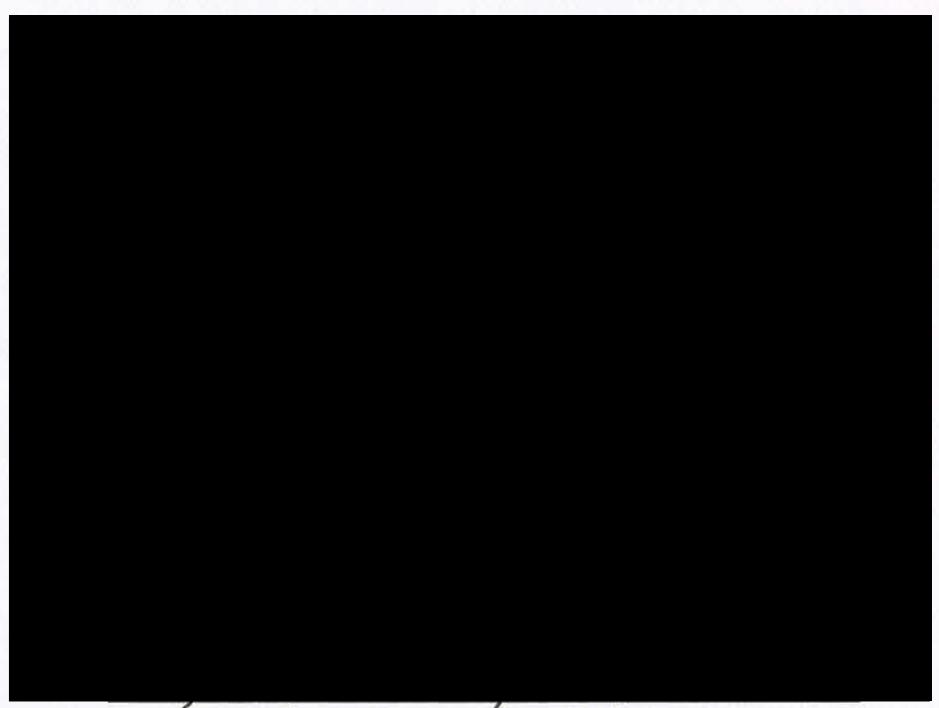

Dean of the Graduate School 


\section{ABSTRACT \\ THE EFFECTS OF THE GOOD BEHAVIOR GAME WITH \\ GENERAL EDUCATION HIGH SCHOOL STUDENTS \\ by Rachel Ritter Mitchell}

August 2012

The purpose of this study was to evaluate the effectiveness of the interdependent group contingency procedure known as the Good Behavior Game (GBG) on decreasing disruptive behaviors in general education high school students. The effectiveness of the GBG has been investigated in many studies as means of managing a variety of behaviors across many developmental levels; however, not all populations have been investigated. Although many studies exist that have utilized the GBG to alter behaviors across ages ranging from pre-school to adulthood, few studies exist in which the GBG has been used with a general education high school population. The present study adds to the literature base of the GBG by extending the versatility of the GBG to a general education high school population. To date, only one other study exists which has examined the effectiveness of the GBG with high school general education students (Kleinman \& Saigh, 2011). Though supportive of the positive effects on disruptive behavior in this population, Kleinman and Saigh had several limitations regarding methodology and only used one classroom which limited the external validity of the intervention. The present study extends this literature base with further investigation of the game, by presenting the game as a Teamwork Competition (TC), and utilizes a separate $\mathrm{ABAB}$ withdrawal design across three classrooms, with withdrawal and reimplementation in two of the classrooms. All three classrooms demonstrated decreases in disruptive behaviors during intervention 
phases. Classrooms also had increases in disruptive behaviors during the withdrawal phase. Teachers and students found the GBG/TC to be acceptable for use in their classrooms. These results support the use of a modified version of the GBG in high school classrooms. 


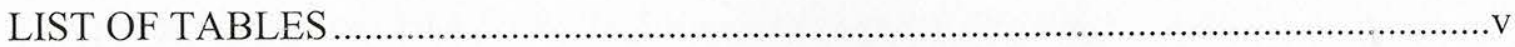

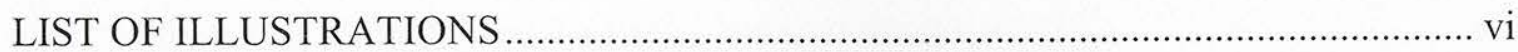

CHAPTER

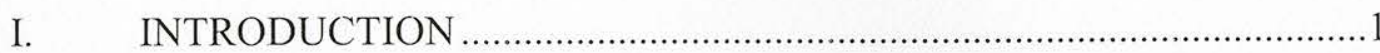

Interdependent Group Contingencies in a High School Setting

Good Behavior Game

Purpose of the Present Investigation

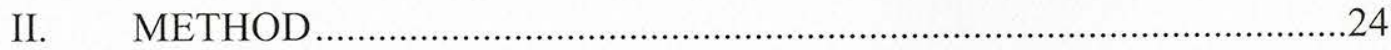

Participants and Setting

Materials

Dependent Variables, Observation Procedures, and Data Collection

Procedures

Design and Data Analyses



Effects on Disruptive Behavior

Teacher Acceptability

Student Acceptability

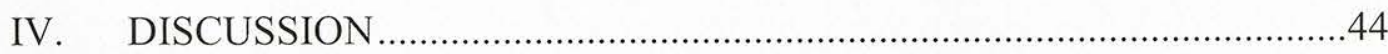

Research Questions

Limitations

Future Research

Implications 


\section{LIST OF TABLES}

Table

1. Mean Percent of Total and Individual Disruptive Behaviors ...............................43

2. Percent of students who Endorsed items of Modified CIRP ................................47 


\section{LIST OF ILLUSTRATIONS}

Figure

1. Disruptive Behavior Across Phases for Classrooms A, B, and C.........................41

2. Off-Task, Out-of-Seat, and Inappropriate Vocalizations Across Phases for Classrooms A, B, and C 


\section{CHAPTER I}

\section{INTRODUCTION}

In order to provide students with a safe and cohesive learning environment, teachers must have effective classroom management procedures in place. According to Durmuscelebi (2010), classroom management pertains to a variety of "proactive, well established, and consistent techniques and practices" used by teachers to control student behavior (p. 377). Students of typical development as young as those in lower elementary school have the capability to understand their actions and make decisions based on that understanding (Oldfather, 1993). Therefore, it is the teacher's responsibility to ensure students understand what is appropriate in the classroom and hold students accountable for their behavior.

Westling (2010) reported that most general and special education teachers did not use effective strategies in their classrooms or receive support for handing challenging behavior. This is a very important and widespread issue in any classroom setting. If the teacher is unable to manage the classroom effectively, precious instructional time can be lost. In another study focusing on teachers' perceptions of student behavior, teachers tended to concentrate on individual students' behavior rather than the class as a whole (Tillery, Varjas, Meyers, \& Collins, 2010). Focusing on individual students' behavior can be time consuming and result in a teacher's inability to recognize and reward those students who are behaving appropriately. This strategy is particularly problematic when there are multiple disruptive students, which in turn, may result in loss of instructional time and learning opportunities for the class as a whole. 
One problem with some teachers' choice of individualized discipline procedures for disruptive behavior is that students may find the consequence reinforcing. Some students' disruptive behaviors may be maintained by attention, and for these students, attention for appropriate behavior may be necessary to reinforce the appropriate behavior and avoid disruption (Shaw \& Simms, 2009). In other situations, a teacher may choose to interrupt ongoing instruction by sending a disruptive student out of the class and to the office. In this case, the teacher must spend several minutes addressing the behavior and filling out a form. The disruptive student is then removed from the classroom, allowing that student to escape whatever task was occurring in the classroom, and further disciplinary actions are left up to administrators. Administrative consequence is particularly problematic for high school students, for whom some of the most common disciplinary actions impede learning and result in loss of education. In a study conducted by Winbinger, Katsiyannis, and Archwamety (2000) using public schools in Nebraska, the authors found that secondary schools face greater rates of inappropriate behaviors and that secondary administrators have stronger beliefs in the benefits of in- and out-ofschool suspension when compared to those of elementary administrators. Fortunately, there are many useful procedures available for teachers aimed at effectively monitoring the classroom as a whole by offering reinforcement and/or mild punishment contingent on target behaviors or expectations of the group. This type of classroom management, known as a group contingency, allows the teacher to focus on the group as a whole and all behaviors rather than just one or two students and their inappropriate and/or disruptive behavior.

Procedures that focus on maintaining appropriate behavior at the class-wide level are also consistent with Positive Behavioral Intervention and Support systems (PBIS), 
which is popular in many school districts (Sugai et al., 2000). PBIS is a range of schoolwide and individualized strategies used to achieve important social and learning outcomes while preventing problematic behaviors in all students, regardless of disability (Sugai et al., 2000). PBIS utilizes a three-tiered system of behavioral management which includes a number of key features including: a prevention-focused continuum of support, proactive instructional approaches to teaching and improving social behaviors, conceptually sound and empirically validated practices, systems change to support effective practices, and data-based decision making (Sugai \& Horner, 2002). The tier system involves implementing a structured support for all students and providing more specialized or individualized support for students who are elevated throughout the tiers. Tier I of the PBIS system offers support to all students and focuses on primary prevention at the school and class-wide level. Tier II is used for smaller specialized groups of students who exhibit at-risk behaviors. The final tier (Tier III) is used for students who have been designated as having high-risk behaviors and utilizes a specialized intervention on the individual level.

One way to incorporate PBIS at the Tier I level is by using group contingencies in the classroom. There are three forms of group contingencies: dependent group contingences, independent group contingencies and interdependent group contingencies. A procedure utilizing a dependent group contingency offers the same response to all group members, but is contingent on only select members; for instance, offering the entire group a reward as long as the lowest score on a test is above a certain criterion (Litow \& Pumroy, 1975). An independent group contingency focuses more on an individual contingency, and although the same criterion applies to all group members, access to reinforcement is contingent on each individual's performance (Theodore, Bray, 
Kehle, \& Dioguardi, 2004). A classroom with an independent group contingency might offer free time to each student who achieves a set criterion or higher on a test. As with a dependent group contingency, an interdependent group contingency offers the entire group access to the same consequence, but also requires collective behavior to access reinforcement (Tingstrom, Sterling-Turner, \& Wilczynski, 2006). Interdependent group contingencies offer several variations with regard to classroom implementation; for example, every member of the group may be required to meet the set criterion, the group may be expected to achieve a certain average, or a certain percentage of group members may have to meet the criterion in order to gain access to reinforcement (Theodore et al., 2004).

Group contingencies may be superior to individual interventions for classroom management and are effective across a broad range of populations (Theodore et al., 2004). Gresham and Gresham (1982) demonstrated success with group contingencies with 6- to 10-year-old students with mild mental retardation in a self-contained classroom. The authors used an $\mathrm{A} / \mathrm{B} / \mathrm{C} / \mathrm{D} / \mathrm{A} / \mathrm{B} / \mathrm{C} / \mathrm{D}$ design to examine the success of all three possible group contingencies. All of the group contingencies improved classroom behavior. The dependent and interdependent group contingencies were more dramatic in their effects and both effectively decreased the disruptive behavior in the classroom, with the most dramatic decrease during the interdependent contingency.

One popular and successful procedure utilizing an interdependent group contingency is the Good Behavior Game (GBG). The GBG's easy implementation in classroom settings and success at lowering target behaviors has led to its popularity among teachers (Tingstrom et al., 2006). In the original study (Barrish, Saunders, \& Wolfe, 1969), a teacher divided her fourth-grade class into two teams. The teacher 
informed the students that they would play a game during a specific class period each day and if a student broke one of the rules, that student's team would receive a mark. The teacher displayed the marks on a blackboard for the class to see and the team with the fewest marks won the game. For the game, a criterion of five marks was set. If both teams received no more than five marks, both teams won the game and members of both teams were allowed access to the privileges. The authors targeted lowering the frequency of student out-of-seat and talking-out behaviors. During baseline, the median number of intervals with talking-out behavior was $96 \%$ and out-of-seat was $82 \%$. After implementing the game in the classrooms, talking-out decreased to $19 \%$ and out-of-seat decreased to $9 \%$. The drastic decreases in behavior during phases help to establish a functional relationship between the implementation of the game and the decrease in occurrences of both behaviors. The GBG has since been identified as a well-established strategy for managing disruptive/aggressive behavior in the elementary school classroom setting (Franklin, Harris, \& Allen-Meares, 2006).

The GBG has many advantages when implemented as a classroom management procedure. The game offers reinforcement for teams of students who do not exceed a criterion or exhibit the least amount of inappropriate behavior. Therefore, the GBG differentially reinforces low rate behaviors by rewarding students for exhibiting a low frequency of target inappropriate behavior during the class period (Litlow \& Pumroy, 1975). In some cases, however, appropriate behavior is targeted and differential reinforcement of incompatible behavior is used. In such cases the student is reinforced for the appropriate and incompatible or alternate behavior and cannot exhibit the inappropriate behavior simultaneously (Tingstrom et al., 2006). 
Although the GBG is best known for its success in the classroom with inappropriate behaviors, since Barrish et al.'s original study, others have successfully adapted the GBG for use with a variety of behaviors in various settings. Numerous authors have created and applied modifications of the GBG and have been able to successfully address a variety of target behaviors including oral hygiene and work productivity (Lutzker \& White-Blackburn, 1979; Swain, Allard, \& Holborn, 1982). Although there are countless studies examining the effectiveness of the GBG with a wide array of participants, there is little literature on applications of the game with general education high school students. Although modified versions of the GBG have shown versatility, yielding success with children as young as preschool and also with students in a general education sixth grade physical education class (Hunt, 2010; Patrick, Ward, \& Crouch, 1998; Swiezy, Matson, \& Box, 1992), the procedure has been extended to older students in only one study (Kleinman \& Saigh, 2011).

Although group contingencies, particularly interdependent ones, are believed to be superior to independent contingencies, only a few studies exist in which interdependent group contingencies have been used in the high school setting (Christ \& Christ, 2006; Schanding \& Sterling-Turner, 2010). The following sections include a brief review on studies demonstrating interdependent group contingencies in high school settings followed by a review of the wide array of literature focusing on the implementation of the GBG and its modifications, organized by population and participant age.

Interdependent Group Contingencies in a High School Setting In a study conducted by Christ and Christ (2006), the authors examined the effects of an interdependent group contingency with three high school inclusion classrooms. 
The intervention aimed to increase the level of academic engagement among students, reduce frequency of disruption by students, and reduce the frequency of teacher corrections for undesirable or disruptive student behaviors. The interdependent group contingency involved the use of an automated feedback device and was designed to require minimal effort from the teacher. The automated feedback device, a digital scoreboard, provided positive feedback for students using a timer and a delivery of digital tokens or points. The teacher was able to use a remote control to reset the interval when disruptive behavior occurred. Each time a two-minute interval passed with no disruptive behavior, the class received a point on the scoreboard. Upon reaching the pre-set goal of 17 points, a reward was delivered. A multiple baseline with withdrawals was used to evaluate the effectiveness of the procedure. The intervention was successful in reducing disruptive behavior and teacher corrections as well as increasing active engagement and instructional time. The teacher also rated the intervention as highly acceptable.

In another study utilizing an interdependent group contingency in a high school setting, Schanding and Sterling-Turner (2010) examined the effect of a mystery motivator intervention on problematic behaviors, including off-task, out-of-seat, and inappropriate vocalizations of three target students as well as their classmates in a ninth grade biology class. The mystery motivator intervention involved informing the classroom of a game that would be played in which they could earn rewards. If the class followed three classroom rules, they had the opportunity to draw for a chance at a reward. If they met the criterion for the game, they were allowed to draw a slip of paper from an envelope. If the slip of paper was a motivator slip, the class earned a reward listed in a separate envelope; if the students pulled a slip with the letter X on it they were congratulated on their behavior and reminded they could win an opportunity at the reward the following 
day. Using an $\mathrm{A} / \mathrm{B} / \mathrm{A} / \mathrm{B} / \mathrm{A} / \mathrm{B}$ withdrawal design to evaluate the effects of the procedure, results indicated that there was a decrease in problem behaviors of the targeted students as well as the rest of the students in the class.

\section{Good Behavior Game}

\section{General Education Preschool}

Though widely used, only two studies have examined the GBG in preschool settings in either its original or a modified form to alter behavior (Hunt, 2010; Swiezy et al., 1992). The results of these studies support the effectiveness of the GBG for altering behaviors across various developmental levels. Targeted behaviors varied across the two studies, and included behaviors such as compliance,"noncompliance, aggression, and inappropriate vocalization.

In the first study of the effectiveness of the GBG with preschool aged children (Swiezy et al., 1992), a variation of the GBG using a multiple baseline design-within subject pairs and across therapists with a changing criterion targeted compliance in four preschool children, two females and two males. Unlike the original version of the GBG used by Barrish et al. (1969), the game was applied in an analog setting, and the teams were composed of only two pairs of children rather than an entire classroom. In this modification, the game focused on rewarding the appropriate target behavior of compliance rather than focusing on inappropriate behavior and response cost procedures.

GBG sessions and observations occurred in a resource room three times a week for 15 minutes. Each of the pairs completed sessions alone. Therefore, each pair's performance and ability to win the game was independent of the other pair, and there was no competition between the two teams. An additional modification of the game included the use of a puppet called Buddy Bear as the session instructor. The authors targeted 
joint compliance from the pair of students. Each time the pair jointly complied with Buddy Bear's instruction, the pair was rewarded with a colored smiley face or dinosaur, which was then displayed on a felt board. For each session, a criterion was set. After reaching the criterion for two sessions, the criterion was increased. The results indicated increased levels of compliance for both pairs during sessions. Although generalization occurred across therapists, there was no evidence of generalization across settings (Swiezy et al., 1992).

There are several limitations in the Swiezy et al. (1992) study. In terms of internal validity, no integrity data were collected. Therefore, it is not possible to know whether or not changes in the dependent variable were directly related to the GBG. There were also threats to external validity. The sessions and observations were not conducted in a naturalistic setting. Instead of conducting the intervention in the students' classroom, the sessions were performed in a separate resource room. Therefore it is unknown if the results of the study are generalizable to a classroom setting. Additionally, a puppet was used to provide instructions and feedback rather than a teacher. Also, only a few students were used to form pairs rather than the entire classroom. This makes the generalizability of the intervention with larger groups unknown.

In an unpublished thesis, Hunt (2010) used a nonconcurrent multiple baseline design across three preschool, Head Start classrooms to assess the effectiveness of the GBG in decreasing disruptive behavior. Participants included three target students as well as classroom peers. Hunt targeted inappropriate vocalizations, noncompliance, and aggression and used the original version of the GBG, as introduced by Barrish et al. (1969), introducing the game following baseline data collection. The GBG was effective in decreasing disruptive behavior across classrooms as well as with target students. 
According to Hunt, procedural integrity was quite low at times (67\%) which required additional teacher training after implementation. Additionally, the criterion for the GBG was not based on baseline data and was, therefore, set too high at times, becoming unattainable for some students.

\section{General Education Elementary School}

In contrast to the amount of literature base for the GBG of other age groups, investigations of the GBG utilizing elementary school aged participants (grades K-6) encompass the largest group of studies. Within this body of literature on the GBG, authors have found the GBG to be an effective procedure for not only decreasing disruptive behavior in this age group, but also for increasing appropriate behavior, increasing work completion and accuracy, increasing appropriate social behaviors and volleyball skills, and increasing oral hygiene (Bostow \& Geiger, 1976; Darch \& Thorpe, 1977; Darveaux, 1984; Fishbein \& Wasik, 1981; Maloney \& Hopkins, 1973; McCurdy, Lannie, \& Bardabas, 2009; Medland \& Stachnik, 1972; Mudgal, 2004, 2006; Patrick et al., 1998; Robertshaw \& Hiebert, 1973; Saigh \& Umar, 1983; Swain et al., 1982).

Robertshaw and Hiebert (1973) used a modified version of the GBG that they called the Good Astronaut Game with a first grade classroom. The authors used the game to increase attention-to-task behavior in 24 students and collected independent data on one target student as well. Unlike the original study by Barrish et al. (1969), the students were divided into four teams. Rather than earning marks against the team, each time students completed a worksheet they earned a token for their team. Tokens were displayed on a board using spaceships and the board was filled with other space themed pictures. At the end of the day, teams were able to move their spaceship according to the tokens earned and the team with the most tokens was able to access reinforcers. 
Data were collected during 30-minute seatwork periods. Data collectors recorded the target student's attentive behaviors and the number of worksheets completed by the target student as well as the entire class. Results indicated an increase in both attentiveness to work and number of worksheets completed; however, the use of an A/B design weakens the study because there is no way to account for any confounds or alternative explanations for the increases.

In a study using 22 first graders and 23 second graders in a multiple baseline across classroom design, Swain et al. (1982) used a modified version of the GBG called the Good Tooth Brushing Game to increase dental hygiene. Oral hygiene was calculated using dissolving red tablets that colored to display any debris on the children's teeth; the Simplified Oral Hygiene Index (OHI-S) was used to calculate the amount of debris. Initially, all students were given a toothbrush, toothpaste and red tablets and were given information on proper oral hygiene; however, no information about the team based competition was given. During baseline, four students were randomly selected, without replacement, to have their teeth examined. Using the OHI-S the amounts of debris of the students were determined. After baseline data were collected, the game was introduced to the students. Each day during the Good Tooth Brushing Game four children were, again, randomly selected to represent their team. Whichever team had the cleanest teeth would win for the day. Results suggest that the introduction and use of the game decreased the amount of debris and increased oral hygiene for the participants.

Bostow and Geiger (1976) used the GBG to decrease out-of-seat behavior, talking-out behavior, lack of attention to assigned task, and bothering neighbors with second graders. The authors did not incorporate any modifications to the game. As in Barrish et al. (1969), the class was divided into two teams, and each time a student 
performed a target behavior he/she earned a mark against their team. The authors evaluated the game using an $\mathrm{A} / \mathrm{B} / \mathrm{A} / \mathrm{B}$ withdrawal design. Results showed a decrease in all targeted disruptive behavior.

The GBG has also been successful cross-culturally as demonstrated by Saigh and Umar (1983) with second graders in Sudan, Africa. In this study, Saigh and Umar targeted aggression, seat leaving, and talking. As in the original study, students were divided into two teams and each time a student violated any of the rules, the student's team received a mark (Barrish et al., 1969). The authors used victory tags, recess and a sticker chart as rewards for the game. An $\mathrm{A} / \mathrm{B} / \mathrm{A} / \mathrm{B}$ design was used to evaluate the effects of the game on students' behavior. During baseline and withdrawal phases, aggression occurred $8.5 \%$ of the intervals, talking occurred $12 \%$ of the intervals and seat leaving occurred $9.6 \%$ of intervals. After implementing the game, aggression decreased to $3.5 \%$, talking to $4.7 \%$, and seat leaving to $1.7 \%$ of intervals. Each additional phase change demonstrated that the game was associated with a decrease in all target behaviors. The results of this study demonstrate that the GBG can be used to effectively manage behavior across cultures.

One criticism of the GBG is that it punishes inappropriate behavior and does not teach or reinforce appropriate alternative behaviors. In an effort to address these limitations of the GBG, Darveaux (1986) modified the GBG by pairing it with a token reinforcement system in an effort to reinforce appropriate behaviors. This modification, the Good Behavior Game Plus Merit, was used to both reduce disruptive behavior and improve assignment completion. Although the game was used in a second grade classroom of 24 students, the target participants were two boys who were at high-risk for placement in a behaviorally impaired class. The class was divided into two teams, with 
one of the target students on each team. Like the original study conducted by Barrish et al. (1969), when students performed the targeted disruptive behavior their team received a mark; however, the game varied due to the merit portion of the modification. Students were awarded merit cards contingent on $75 \%$ accuracy of class work and participation. Once a team earned five merits, they were able to remove one of the inappropriately earned marks against their team.

Both disruptive behavior as well as assignment completion were tracked. Using an $\mathrm{A} / \mathrm{B} / \mathrm{A} / \mathrm{B}$ design, results from the study showed that during the $\mathrm{GBG}+$ Merit package phases, there was a dramatic decrease in disruptive behaviors and increase in assignment completion for the target students as well as an increase in assignment completion for the entire class compared to baseline phases. Following the removal of the intervention from the class disruptive behavior and assignment completion returned to levels similar to those during baseline.

In another unique take on the original study, Darch and Thorpe (1977) used a modified GBG called the Principal Game to increase on-task behavior. Unlike the traditional version of the GBG, the Principal Game targeted on-task behavior rather than off-task behavior. The study focused on the 10 students in a fourth grade classroom that had been ruled the most deviant by their teacher. During the Principal Game, the class was divided into five teams based on the seating chart. During the game, students were given six opportunities to earn a point. In order to earn a point, the entire team had to be on-task when a timer sounded. Regardless of the performance of other teams, each team could win the game by earning five of the possible six points. The school principal delivered positive attention to the teams who won the Principal Game at the end of the period. 
The effectiveness of the Principal Game was evaluated using an A/B/A/C/A design. After collecting baseline data, the Principal Game was introduced during the second phase. Following the introduction of the game, a withdrawal phase was implemented. During the fourth phase, an independent contingency was put in place. During this time students earned consequences for individual behavior and those behaviors were in no way impacted by the group. This phase was followed by an additional withdrawal phase in which all interventions were removed. Results indicated that the Principal Game increased on-task behavior above baseline levels as well as above levels during the independent contingency.

A study conducted by Medland and Stachnik (1972) partially replicated Barrish et al.'s (1969) investigation and also included systematic analysis of the GBG using a slightly modified version with a $5^{\text {th }}$ grade reading class. The effectiveness of the intervention in decreasing talking-out and out-of-seat behaviors was evaluated using an $\mathrm{A} / \mathrm{B} / \mathrm{A} / \mathrm{C} / \mathrm{D} / \mathrm{B}$ phase change design. The game components consisted of rules, light indicators, and group consequences of extra recess or free time. Modifications to the game included the use of a light indicator, which provided feedback for when an error (e.g., inappropriate vocalization or being out of seat) was being made in addition to the traditional marks utilized by Barrish et al. (1969). Additionally, students on the losing team, were allowed the opportunity, if necessary, to vote out a teammate for one day whom they believed to be a saboteur of the game.

The $\mathrm{A} / \mathrm{B} / \mathrm{A} / \mathrm{C} / \mathrm{D} / \mathrm{B}$ design included six phases: baseline ${ }_{1}$, game $_{1}$, baseline $_{2}$, rules, rules + lights, and game 2 . Following implementation of the modified GBG (game 1 ), a withdrawal phase occurred (baseline $e_{2}$ ). During this phase, the game was not played and the teacher utilized past classroom management procedures as she had during baseline. 
The following phase involved explaining the rules only with no game or related consequences (rules). The next phase involved explaining the rules as well as the light indicator feedback (rules + lights) but did not involve the game or any of its consequences. For the final phase $\left(\mathrm{game}_{2}\right)$, the modified $\mathrm{GBG}$ was reintroduced to the classroom. Results indicated that both phases of the game produced meaningful change in all of the targeted behaviors. Results also indicated similar results in the rules + lights phase. A limitation of the study includes possible sequence or order effects, as well as possible carry-over effects, specifically regarding the rules + lights phase to the game ${ }_{2}$ phase.

Maloney and Hopkins (1973) implemented a version of the GBG called the Good Writing Game which targeted improving compositional variables of stories written during a non-remedial summer school session with 14 students from fourth, fifth, and sixth grades. Each day the students had to exceed the set criteria in order to earn the reward. Also, if the students were not able to exceed the criteria, the students were still able to access the reward if the point difference between the two teams was less than 100 points.

The authors used a multiple baseline across parts of speech and sentence structure to improve three dependent variables: the number of different adjectives within written stories, the number of different action verbs within stories, and the number of different sentence beginnings. For the first phase of the Good Writing Game, winning was contingent on the number of different adjectives in the students' written stories; however, data were collected for all three of the target variables. During the second phase, the contingency changed to only the number of different action verbs within the stories and again all variables were tracked. During the third phase winning was contingent on the number of different adjectives, action verbs, and the number of different sentence 
beginnings. The results of the study indicate that the Good Writing Game was effective in improving the number of targeted parts of speech and sentence structure.

In another study using fourth, fifth, and sixth grade students, Patrick et al. (1998) targeted the occurrence of appropriate and inappropriate social behaviors and appropriate skill attempts during a volleyball unit in physical education classes. Like the original study, students were divided into teams; however, unlike the original study, students earned points based on displaying appropriate behaviors (Barrish et al., 1969). The game also featured a response cost component in which the display of inappropriate behaviors resulted in the removal of points previously earned. Another modification was the use of a previously set criterion, so all teams could win the game regardless of the score of the other team. A multiple baseline design across classes was used to evaluate the effectiveness of the intervention. The intervention showed an immediate increase in appropriate behavior and decrease in inappropriate behavior; however, there was no change in correct or incorrect skill attempts by the students.

In a study focusing on academic behaviors, Mudgal (2004) modified the GBG in a version called the Good Classwork Game (GCG). Participants for the GCG included three target students from three separate elementary-level classrooms, one in kindergarten, one in fourth and one in fifth grade, as well as their classroom peers. For the GCG, the experimenter targeted three behaviors: work completion, work accuracy, and off-task behavior. Although Mudgal tracked all behaviors for data collection purposes, only the appropriate behaviors of work completion and work accuracy were addressed as part of the game and received consequences. Mudgal anticipated that offtask behavior would simultaneously decrease with the increase of appropriate behaviors. An $\mathrm{A} / \mathrm{B} / \mathrm{A} / \mathrm{B}$ withdrawal design was used to demonstrate the effectiveness of the GCG. 
Although the GCG intervention was successful at increasing work completion and decreasing off-task behavior of the target students, there was no improvement in work accuracy (Mudgal, 2004).

Mudgal continued her examination of the Good Classwork Game in a follow-up investigation (Mudgal, 2006). In this study, she employed a cross-over phase change design to examine the effect of non-randomized compared to randomized game criteria on increasing math accuracy and completion. Mudgal's participants included four target students in third, fourth, and fifth grade, as well as their classroom peers. Each classroom was randomly assigned to the $\mathrm{A} / \mathrm{B} / \mathrm{C} / \mathrm{B}$ or $\mathrm{A} / \mathrm{C} / \mathrm{B} / \mathrm{C}$ design. Non-randomized game criteria (criteria for work completion and accuracy based on baseline levels) were implemented during phase B and randomized game criteria (based on different criteria established during the non-randomized phase) were implemented during phase C. In order for a team to win the "game" their criteria had to meet or exceed that which was set, depending on the phase. Both intervention phases appeared to be equally effective at increasing math work completion and accuracy.

McCurdy et al. (2009) applied a modified version of the GBG called the Lunchroom Behavior Game (LBG) in the cafeteria of an urban elementary school. The study targeted disruptive behavior to include out-of-seat, play fighting, physical contact with force, throwing objects, and screaming. During the game, school staff developed expectations for the cafeteria, taught these expectations, and explained the LBG to their students one week prior to implementation. Teams for the LBG were comprised of an entire class. Staff members monitored the behaviors of the students and tallied marks on a large dry-erase poster. Mystery weekly criteria were set and teams who did not exceed the criterion were announced over the intercom the following Monday. In addition, 
winners with the lowest points from each lunch period received rewards which included edible items, small tangibles and certificates for movie time and class parties.

The authors used a multiple baseline across the three lunch periods to measure the impact of the LBG on the disruptive behavior of the students over four weeks. Results of the LBG were consistent with other studies of the GBG and resulted in clear and immediate decreases in disruptive behavior.

\section{General Education High School}

Only one study has utilized the GBG with a general education high school population (Kleinman \& Saigh, 2011). Following the introduction of a new teacher into a ninth grade history class in a multi-ethnic New York City high school, Kleinman and Saigh implemented the GBG with the classroom in an effort to decrease disruptive behavior including talking or verbal disruption, aggression or physical disruption, and seat leaving. The class was comprised of 15 males and 11 females with a mean age of 15.39 years. Of the 26 students, six were African American, 19 were Hispanic, and one did not report ethnicity. The GBG was modified in that it was not presented as a game, but instead as an opportunity for the students to earn prizes. Also, target behaviors were presented as "expectations" (p.102) rather than rules.

The authors had the students complete a reinforcement preference questionnaire prior to treatment implementation to determine the daily and weekly prizes. The rewards included cost effective items limited to approximately $\$ 15$ a week such as candy and a pizza or cupcake party. The effects of the GBG were evaluated using an $\mathrm{A} / \mathrm{B} / \mathrm{A} / \mathrm{B}$ withdrawal design. The authors initiated a week long adaptation period prior to baseline to limit reactivity caused by the observers. During this time the observers joined the classroom and collected data on the presence or absence of behaviors, however, these 
data was not provided. During week two, the class was divided into two teams and baseline data were collected. The GBG was implemented in the classroom during the third week. During the fourth week, a withdrawal phase began, during which the teams remained intact and classroom expectations were read aloud each day; however, inappropriate behavior was handled in the teacher's traditional manner. The GBG was reintroduced during the fifth week in the same manner as it had been initially. The results of the study include an immediate change in level of all disruptive behaviors from baseline following the game's introduction. Withdrawal of the game during the fourth phase resulted in an increase in level similar to those of baseline. The re-introduction of the game and follow-up phases resulted in levels consistent with the initial introduction of the game. These results provide initial support for the GBG as an effective tool for general education high school students.

Several limitations exist with the study. Phase changes were decided based on the beginning of a new week rather than the data. Though this did not end up causing any major issues, there was an increasing trend in the data prior to the withdrawal phase. Experimental control would have been improved by data-based decision making. Additionally, because the classroom was comprised of all ninth grade students, it is not possible to say if the GBG is generalizable to older high school students or those of different educational or demographic backgrounds. Replication and additional studies are needed.

\section{Special Education}

Multiple studies have used the GBG and some of its modified forms in special education settings to decrease disruptive behavior, increase academic behavior, or both (Davies \& White, 2000; Gresham \& Gresham, 1982; Hegerle, Kesecker, \& Couch, 1979; 
Johnson, Turner, \& Kornarski, 1978). Again, these studies support the GBG as effective for altering behaviors across various developmental levels.

Hegerle et al. (1979) were among the first to utilize the GBG with a special education population. The authors applied a modified version of the GBG with a selfcontained classroom, targeting out-of-seat behavior, talking-out behavior, and tattling which was added four days after the implementation of the GBG. The authors provide no information regarding the age or grade of the students in the study. The experimenters divided the 22 students based on gender and also allowed certain students who earned a large number of marks to be omitted from counting against the team, a rule which was inserted seven days into implementation due to trouble students. The modified version also incorporated a token system, which allowed the winning team to place a star on a Victory Chart as well as a changing criterion component. Although graphs were not included in the published study, the authors reported that the results indicated that the implementation of the GBG was effective for reducing target behaviors.

Johnson et al. (1978) designed a study examining the effectiveness of the GBG in decreasing disruptive behavior and increasing academic behavior in students who had been removed from regular classes due to low achievement-motivation. The authors implemented the game in a third and fourth grade transitional class. The authors targeted appropriate behavior, disruptive behavior and teacher attention in the study. A multiple baseline design across settings, subjects and time periods was used to evaluate the effectiveness of the GBG. The third grade class was divided into three teams and the fourth grade class was divided into two teams based on the teachers' preference. The teachers also elected captains from each team to be responsible for counting the marks 
each day. Results from the game showed a dramatic decrease in disruptive behavior as well as teacher attention to disruptive behavior.

In an investigation of the effectiveness of group contingencies, Gresham and Gresham (1982) implemented three separate programs during different phases with a self-contained classroom. The authors used an $\mathrm{A} / \mathrm{B} / \mathrm{C} / \mathrm{D} / \mathrm{A} / \mathrm{B} / \mathrm{C} / \mathrm{D}$ design to compare the different forms of group contingency. During baseline, the classroom was conducted using the teacher's normal procedures. During the B phase, the GBG was implemented with no modifications to the Barrish et al.'s original study (1969). The following phase utilized a dependent group contingency. At this time, the two most disruptive students were appointed as team captains. If the team captains exhibited five or more disruptive behaviors, the teams were not able to access reinforcers. During the D phase, the authors employed an independent contingency in which students competed independently for reinforcement. As long as a student received fewer than five marks, the student received the reinforcer (Gresham \& Gresham, 1982).

The experimenters' use of an $\mathrm{A} / \mathrm{B} / \mathrm{C} / \mathrm{D} / \mathrm{A} / \mathrm{B} / \mathrm{C} / \mathrm{D}$ design resulted in some limitations in the interpretation of results produced. Although the results showed that the interdependent and dependent contingency phases produced more desirable results for decreasing disruptive behavior, the design was not counterbalanced. Because the phases occurred in the same order, it is not possible to know whether order effects or carry-over effects contributed to the results. Furthermore, phase changes occurred as a function of time, further limiting the ability to make phase to phase comparisons.

In another study utilizing special education students, Davies and White (2000) used a modified version of the GBG to target inappropriate vocalization with four third grade students diagnosed with Attention Deficit Hyperactivity Disorder (ADHD) as well 
as their classroom peers. The study involved matching the four target students with ADHD with comparison peers without ADHD diagnoses. This modified version of the GBG incorporated a self-regulating component which involved a chart located in the middle of the classroom tables. These charts were divided into three sections: a green section, a blue section, and a red section and each team had five Velcro dots on the charts. If a member of the team displayed one of the targeted inappropriate behaviors, he was to move a dot from the green section to the blue section. If the student did not move the dot appropriately, the teacher moved the dot into the red section. At the end of the game, each team needed at least one dot in the green section to win the reward. In addition to the group chart, each child had individual charts to track which students were responsible for each behavior. At the end of each day, students received teacher and peer feedback on their performance. An $\mathrm{A} / \mathrm{B} / \mathrm{A} / \mathrm{B}$ withdrawal design was used to assess the effects of the intervention. Results indicated that the target behavior decreased for all students. A major limitation to the study was that mid-way through the study, the classes changed, three of the matched peers were moved to another classroom, and new peers were selected. Additionally, no treatment integrity data were collected.

In a study by Lutzker and White-Blackburn (1979), the GBG was applied using four state hospital residents. The behaviors targeted for the residents included work output, on-task behavior, and staff attention. The game was evaluated using an $\mathrm{A} / \mathrm{B} / \mathrm{A} / \mathrm{C} / \mathrm{A}$ withdrawal design. The game was implemented during the second phase and a feedback-only phase was implemented during the fourth phase. The game produced higher levels of productivity and work output during the GBG phase compared to both baseline phases as well as the feedback-only phase. 


\section{Purpose of the Present Investigation}

Although there have been many studies supporting the effectiveness of the GBG as a classroom intervention, not all areas have been explored. Because disruptive behaviors do not necessarily disappear with age, procedures are still needed to assist teachers with managing them in high school classrooms. Because the current literature base has covered a variety of ages and behaviors, there is a distinct possibility that the GBG can be extended to the general high school population to effectively decrease inappropriate behaviors as well. Introducing the GBG in a high school population may help to enable teachers to handle minor infractions in their classroom and avoid removing students from the academic setting for disciplinary action. To date, only one study exists (Kleinman \& Saigh, 2011) in which the GBG has been used in a general education high school classroom. Additional studies of the GBG with high school students are needed. The present study will apply the GBG in general education high school classrooms, targeting teacher-referred disruptive behavior.

The present study aims to investigate the following research questions:

1. Will the Good Behavior Game/Teamwork Competition (TC) effectively decrease disruptive behavior of general education high school students?

2. Is the Good Behavior Game/Teamwork Competition acceptable to teachers for use in a general education high school classroom?

3. Is the Good Behavior Game/Teamwork Competition acceptable to students for use in a general education high school classroom? 


\section{CHAPTER II}

\section{METHOD}

\section{Participants and Setting}

Participants included three high school classrooms and their teachers at a high school located in a southeastern state referred for participation by administrative referral for classroom disruptive behavior. The school in which the study took place had approximately 1000 students in the ninth through twelfth grades with $89 \%$ of the school's population eligible for free or reduced lunch. The school had been implementing PBIS at the Tier I level for two years at the time of the study and had received a $79 \%$ on the PBIS School-wide Evaluation Tool (SET) the previous year and a 95\% for the current year (Sugai, Lewis-Palmer, Todd, \& Horner, 2005).

Teacher consent was obtained by the primary investigator for inclusion (See Appendix A for Teacher Consent Form). Prior to screening, teachers were briefly interviewed and asked to list and describe behaviors they felt were most troublesome in their classroom. These primary concerns of the teacher, along with the behaviors identified by the teacher and author, were used to operationally define the targeted behaviors for each of the classrooms. Classrooms of teachers who agreed to participate met with the primary investigator then went through a screening process. Teachers and all students in the classroom served as participants and had their behavior monitored by trained observers. All teachers served as interventionists for the study. Because there were no individual student data collected, only teacher consent was obtained for classroom participation. Details of self-reported classroom demographics and intervention agents are provided below. 
Teacher A (Ms. Adams) was a 45-year-old Caucasian female who had taught for eight years; this was her first year teaching at the present school. Ms. Adams earned a Master's degree and had completed some doctoral coursework. She described the students in her referred Transitions to Algebra class, Classroom A, as loud and disruptive. She expressed a great deal of concern about this due to the fact that Algebra is a statetested subject. Classroom A consisted of 21 students. Of those students, 5 were females and 16 were males. Based on student report, Ms. Adams' classroom consisted of 20 African American students and one biracial student (African American/Caucasian). One student was in the twelfth grade, two were in the eleventh grade, and eighteen were in the ninth grade. The average age of the students was 15.23 years (range=14-17).

Teacher B (Mr. Boyd) was a 45-year-old Caucasian male who had taught for five years and for the last three years at the present school. Mr. Boyd described the students in his referred Transitions to Algebra class, Classroom B, as extremely talkative. He noted that the students often spent time drawing, playing with non-task related items (cell phones) and walking around the room without permission. Mr. Boyd's classroom consisted of 24 students. Of those students, 13 were females and 11 were males. Based on student report, Mr. Boyd's classroom consisted of 20 African American students, 1 Hispanic student, and 3 biracial students (African American/Caucasian). All students were in the ninth grade and the average age of the students was 14.7 years (range=14-16).

Teacher C (Mrs. Carmen) was a 39-year-old Hispanic female who had taught for two years and this was her first year teaching at the present school. Mrs. Carmen was an immigrant from a Latin American country. Mrs. Carmen's native language was Portuguese; however, she also spoke English and Spanish fluently. Mrs. Carmen earned a Master's degree prior to teaching. Mrs. Carmen described the students in her referred 
Spanish II class, Classroom C, as very talkative. Mrs. Carmen's classroom consisted of 23 students. Of those students, 16 were females and 7 were males. Based on student report, Mrs. Carmen's classroom consisted of 20 African American students, one White student, one Hispanic student, and one biracial student (African American/Caucasian). Of those students, 7 were in the eleventh grade, 11 were in the tenth grade and 5 were in the ninth grade. The average age of students was 15.58 years (range=14-17).

\section{Materials}

The implementation of the Good Behavior Game (GBG)/Teamwork Competition (TC) intervention included the use of a teacher script (Appendix B), a board on which team names were displayed, and teacher-approved rewards. The use of the script created a consistent way for each of the teachers to present the appropriate rules and game procedures to their classes. The use of the board allowed students to track their performance throughout the game. The board was placed in a part of the room that was easily viewed from all seats and easily accessible to the teacher. This board displayed the team names as well as marks counted against each team for disruptive behavior. Prior to the implementation of the game, students were asked to list items they would like to earn and the teacher and primary investigator developed a list of rewards from those student requested items to present the winning teams. Rewards for all classrooms were of low or no monetary value (homework passes, extra-credit/test points, access to free time, edibles, etc.) Acceptability

Following the end of data collection, the acceptability of the intervention was assessed from both the participating teachers as well as the students in the classrooms. The teacher's acceptability of the GBG/TC was assessed using the Intervention Rating 
Profile-15 (IRP-15; Martens, Witt, Elliottt, \& Darveaux, 1985; Appendix C). The IRP15 is a questionnaire containing 15 questions regarding the intervention using a Likert scale $(1=$ strongly disagree; $6=$ strongly agree). Scores can range from 15 to 90 and the higher a score the higher acceptability of the intervention. Von Brock and Elliott (1987) recognize scores of 52.50 and higher as indicating acceptability and also report that the IRP-15 has a Cronbach's Alpha of .98. Teachers completed the IRP-15 following the final day of data collection.

In addition to the IRP-15, students completed a modified Children's Intervention Rating Profile (CIRP; Witt \& Elliottt, 1985; Appendix D). This form was used to evaluate the high school students' acceptability of the intervention. The CIRP is comprised of seven yes or no questions. Reliability and validity have not been established for the CIRP, however, more agreement answers (i.e., yes) indicate higher acceptability. Like the IRP-15, the students completed this form following the final day of data collection. Modifications to both forms included changing tense of some items from present to past tense as well as the use of word substitutions including changing the word child/children to student(s) to accommodate high school aged participants. An eighth item was also added to the modified CIRP, inquiring about the rewards given during the game, to encompass all areas of students' acceptability. Such minor modifications to such scales have not been found to appreciably affect results with regard to acceptability (Freer \& Watson, 1999).

Dependent Variables, Observation Procedures, and Data Collection

Three dependent variables were measured for each classroom. The specific targeted behaviors were developed according to teacher referral; however, all three teachers reported similar target behaviors and therefore the same behaviors were tracked 
across all three classrooms. Targeted behaviors included inappropriate vocalizations, offtask behavior, and out-of-seat behavior. The behaviors were defined based on the teacher's specific complaints. Inappropriate vocalizations was defined as any voluntary audible verbalization made without teacher permission such as speaking, yelling, humming, singing, and/or whispering. Off-task behavior was defined as the student's attention (eyes/face) directed away from the assignment or instructing teacher for more than three seconds; this may include a student looking at another student, having his or her eyes closed, rummaging through his/her book bag at inappropriate times, or staring/spacing out. Out-of-seat behavior was defined as the student's buttocks breaking contact with his or her seat for more than three seconds without teacher permission.

The primary investigator and trained graduate students served as observers for the three classrooms. Data collection occurred two to four times each week during the referred class period and the observations lasted 20 minutes. Coding sheets had the 20minute observation broken into 120, 10-second intervals (Appendix E). An audio recording (heard via headphones) cued the changing of each interval. For each interval, the observer looked at the interval's target student (for each interval the target student alternated across the entire classroom), until every student had been observed, and then the observer started over with the first student until the 20 minute observation was complete. The observation included partial interval recording, meaning any instance or occurrence of a target behavior in an interval by the target student resulted in that behavior being recorded as present during the interval. As the recording cued a new interval, the observer looked to the next student and recorded whether that interval's target student was exhibiting any of the target inappropriate behaviors at any time during the interval. Observations began approximately five minutes after the start of the period 
to allow the students an opportunity to transition between classes. The data collected for all of the students each day were collapsed into the percent of intervals for each targeted behavior. At the end of each observation, the total percentage of intervals with each target behavior was graphed as a representation of the classroom as a whole. All target behaviors were also collapsed and graphed as the total percentage of intervals with disruptive behavior.

Data collection for the screening process was identical to the method used during data collection for baseline and intervention phases. In order to screen into the study a classroom needed at least $30 \%$ of intervals to include the occurrence of disruptive behavior during the screening observation.

\section{Procedures}

\section{Screening}

Following administrative referral for the study and teacher consent, screening observations were conducted. Teachers conducted class as usual, using standard classroom management procedures, and dealing with appropriate and inappropriate behavior in their typical manner. At this time, all students were monitored in alternating intervals for any of the targeted behaviors. At least one of the targeted behaviors must have occurred in at least $30 \%$ of the intervals in order for the classroom to screen in to the study. This served as the first baseline point for classrooms that screened in. All referred teachers that consented to participate in the study screened in. Teachers who did not consent were provided with appropriate services/recommendations.

\section{Baseline}

Once a classroom screened into the study, baseline data collection began. At this time, the teacher continued to conduct his or her classroom as usual with no additional 
contingencies in place for targeted behaviors. Teachers reported that there were no classroom interventions in place during this time and this was confirmed by anecdotal observations (i.e., observers noted the absence of any intervention materials in the classroom). Data were collected for the three targeted behaviors observing all students in the classroom during alternating intervals. The data for the students were then collapsed to represent the classroom as a whole and were graphed daily.

\section{Teacher training}

Following the collection of baseline data, the teachers were trained on the TC procedures. Training occurred during each teacher's planning period prior to implementation. Training consisted of the introduction of the script and explanation of the TC components, modeling of the script and steps of the TC for the teacher, and monitoring rehearsal of the steps by the teacher. The teacher received feedback following the training session and following each data collection session to ensure that integrity was maintained throughout the study. Feedback included information about any steps a teacher did not complete during a session as well as praise for teachers who implemented with high/perfect integrity. Teachers were required to practice the steps of the intervention with $100 \%$ integrity prior to implementing with their classrooms. If a teacher did not complete at least $80 \%$ of the steps possible, the teacher was retrained (see Appendix F and G for checklist). During the course of the study, only one teacher (Teacher B) required retraining on one occasion. Retraining consisted of repeating the original training steps with the primary investigator.

\section{Preference Assessment}

Following the collection of baseline data, but prior to implementation, teachers administered a brief preference assessment questionnaire to their students (See Appendix 
H). At this time students were able to suggest rewards that they would like to earn and would be willing to work for. Students' responses included edibles (i.e., candy, Cheetos, donuts), homework passes, bathroom passes (which were otherwise limited to the teacher's discretion), bonus points/grades, school supplies (i.e., pencils, erasers, notebooks), and money. All three teachers approved the use of edibles, homework passes, bathroom passes, bonus points and school supplies as daily rewards for the students. All teacher approved rewards were placed in a box and students were allowed to choose from all of the options on any day. All items of monetary value were provided by the author, however, cost of these items was relatively low (\$5-\$10 per week).

\section{Good Behavior Game (GBG)/Teamwork Competition (TC)}

Following baseline data, the teacher introduced the TC to the classroom. At this time, the teacher used the script and followed the steps modeled and rehearsed during prior training. After explaining the rules and expectations of the game, the teacher divided the students into two teams based on the seating chart. The teachers knew about the development of teams prior to data collection so any adjustments to balance the most disruptive students across the two teams could take place prior to baseline data collection. All teachers felt the classrooms were balanced and did not opt to move any students. Each day that observations occurred, the observer(s) also completed a teacher integrity checklist. The teachers were instructed to give the teams generic names (e.g., the red and blue team). Drawing on the school's colors, Classroom A and B had the Gold and Maroon teams and Classroom $\mathrm{C}$ had the Rojo and Amarillo teams. The team names were written on the classroom whiteboard and were easily visible by all students and easily accessed by the teachers. Each time the teacher observed one or more students on a team engaging in one or more inappropriate behaviors, the teacher placed a mark under the 
team of the offending student, and provided feedback to students when necessary (i.e., pointing out or verbalizing names of specific team members when necessary).

Following baseline data collection, a criterion was set based on a private frequency count kept by the teachers during the baseline phase. Frequency counts were kept by the teacher during baseline to demonstrate what the number of marks would be had the game been in place. The criterion was set to $10 \%$ below the mean number of marks during baseline in each classroom so that reinforcers could be reasonably attained. The criteria were 18 marks for Classroom A, 19 marks for Classroom B, and eight marks for Classroom C. The criteria remained constant throughout the game. If both teams met this criterion, meaning both teams had fewer marks than the pre-set criterion, both teams had access to the rewards. If neither team scored fewer marks than the set criterion, then the team with the fewest marks won the reward. This meant that both teams had an opportunity to win the game every day; however, at least one team always won. Observers tracked disruptive behavior multiple times a week and the data were graphed each day.

Design and Data Analyses

The effects of the GBG on reducing disruptive behavior were evaluated using an $\mathrm{A} / \mathrm{B} / \mathrm{A} / \mathrm{B}$ withdrawal design across three classrooms. Phase changes occurred based on the trend, level, and stability of the collapsed targeted disruptive behaviors. Baseline data were collected for four sessions in Classroom A, 10 sessions in Classroom B, and eight sessions in Classroom C. Treatment effects were analyzed visually for level, trend, and variability.

Following the implementation of the TC and a clear, stable treatment effect was evident (based on level, trend, and variability), a withdrawal phase was implemented. 
However, the teacher of Classroom B elected to withdraw from the study prior to withdrawal and re-implementation phases. In Classrooms A and C, during the withdrawal phase the TC was removed and the teachers (A and C) were asked to return to their typical classroom management procedures. Following the withdrawal phases the TC was put back in place for a re-implementation phase in both classrooms (A and C). Treatment effects were analyzed visually for level, trend, and variability.

\section{Procedural Integrity}

During each day of data collection, the observer completed a procedural integrity checklist (See Appendix F and G). Use of the checklist ensured that treatment integrity remained high throughout the course of the intervention implementation phase. The checklist, adapted from Hunt (2010), included questions regarding the adherence to the game rules as well as the awarding of prizes to the game winner(s) (Appendix F and G). Teachers received performance feedback each day regarding any steps missed on the integrity checklist following data collection. If teachers received $100 \%$ integrity, they were given praise for their implementation. Teacher integrity was calculated by dividing the number of steps carried out by the number of total steps possible during the observation and multiplying by 100 to create a percentage. Anytime a teacher failed to complete $80 \%$ of the steps, he or she was retrained.

Procedural integrity was collected during all phases. All three teachers maintained $100 \%$ integrity during baseline sessions. Teacher A and Teacher $\mathrm{C}$ also maintained $100 \%$ integrity during the withdrawal phases. During initial implementation Teacher A's procedural integrity averaged $92 \%($ range $=83 \%-100 \%)$. During re-implementation Teacher A's procedural integrity averaged $98 \%$ (range $=83 \%-100 \%)$. Teacher B's procedural integrity averaged $93 \%($ range $=67 \%-100 \%)$. During one of the intervention 
sessions Teacher B had trouble maintaining consistency regarding recording disruptive behavior and failed to remind students of the daily criterion and required retraining. During initial implementation Teacher $\mathrm{C}$ maintained an average of $98 \%$ procedural integrity (range $=89 \%-100 \%)$ and an average of $98 \%($ range $=85 \%-100 \%)$ during the re-implementation phase.

\section{Observer Training and Interobserver Agreement}

The primary investigator as well as trained graduate students served as observers. Prior to data collection, observers were trained on the exact behavioral definitions of each behavior and the observation method. The operational definitions were also included on data collection sheets to ensure full access to definitions at all times (Appendix E).

Observers practiced data collection in a classroom(s) until they obtained $90 \%$ or higher IOA with the primary investigator for all behaviors. At this point observers were able to enter classrooms independently to observe and collect data.

Two observers collected data during at least $25 \%$ (range $=25 \%-50 \%$ ) of the sessions for each phase for all classrooms. Interobserver agreement (IOA) for disruptive behavior as well as teacher integrity remained above $90 \%$. IOA was calculated separately for each of the three behaviors and for teacher integrity. IOA was calculated by adding the total number of agreements for occurrence and for nonoccurrence of the behavior between the two observers and dividing that number by the total number of intervals and multiplying by 100 .

For Classroom A, IOA was collected for $25 \%$ of baseline sessions, $50 \%$ of initial treatment sessions, $33 \%$ of withdrawal sessions, and $44 \%$ of re-implementation sessions. Total disruptive behavior IOA for Classroom A averaged $97.66 \%$ (range $=93 \%-100 \%$ ). IOA for individual target behaviors for Classroom A was $96 \%$ (range $=94 \%-100 \%)$ for 
off-task behavior, $99.7 \%$ (range $=98 \%-100 \%$ ) for out-of-seat behavior, and $98 \%$ (range $=97 \%-100 \%)$ for inappropriate vocalizations.

For Classroom B, IOA was collected for $50 \%$ of baseline sessions and $44 \%$ of treatment sessions. Total disruptive behavior IOA for Classroom B averaged 98\% (range $=96 \%-100 \%)$. IOA for individual target behaviors for Classroom B was $98 \%$ (range $=$ $94 \%-100 \%$ ) for off-task behavior, $99 \%$ (range $=94 \%-100 \%$ ) for out-of-seat behavior, and $97 \%$ (range $=94 \%-100 \%)$ for inappropriate vocalizations .

For Classroom C, IOA was collected for 38\% of baseline sessions, $38 \%$ of initial treatment sessions, $50 \%$ of withdrawal sessions, and $38 \%$ of re-implementation sessions. Total disruptive behavior IOA for Classroom C averaged 98\% (range $=95 \%-100 \%$ ). IOA for individual target behaviors for Classroom $\mathrm{C}$ was $97 \%($ range $=91 \%-100 \%)$ for off-task behavior, $100 \%($ range $=100 \%)$ for out-of-seat behavior, and $99 \%($ range $=96 \%$ - 100\%) for inappropriate vocalizations.

IOA for procedural integrity was also collected and calculated by adding the total number of agreements regarding the completion/incompletion of TC steps between observers and dividing that number by the total number of agreements possible. That number was then multiplied by 100 . Procedural integrity was collected during all data collection sessions and therefore the percentage of IOA sessions for procedural collection was identical to that of IOA (range $=25 \%-50 \%$ of phases). There was $100 \%$ agreement of all procedural integrity observations. 


\section{CHAPTER III}

\section{RESULTS}

\section{Effects on Disruptive Behavior}

Figure 1 includes the percentage of intervals in which total disruptive behavior collapsed across individual behaviors occurred across phases in each classroom. During baseline, students in Classroom A (top panel) displayed disruptive behaviors during an average of $67 \%$ (range $=60 \%-73 \%)$ of intervals. There was an immediate reduction in targeted disruptive behavior following the implementation of the TC. The percentage of intervals in which students displayed disruptive behaviors decreased to an average of $30 \%$ (range $=23 \%-33 \%$ ) during the first TC phase. To further increase experimental control a withdrawal phase occurred in which the intervention was removed from the classroom for a short time. During this phase the percentage of intervals containing disruptive behaviors increased to an average of $50 \%$ (range $=49 \%-51 \%$ ). Following this phase the TC was re-implemented and again occurrence of disruptive behaviors decreased to an average of $26 \%$ (range $=21 \%-35 \%)$ of intervals. For Classroom A there were no overlapping data between intervention phases and non-intervention phases.

In addition to tracking overall collapsed disruptive behaviors, individual behaviors were tracked and graphed and can be seen in Figure 2 and Table 1. For Classroom A (top panel), during baseline off-task behaviors occurred during an average of $61 \%$ of intervals (range $=55 \%-69 \%$ of intervals), out-of-seat behavior occurred in an average of $6 \%$ of intervals (range $=4 \%-8 \%$ of intervals), and inappropriate vocalizations occurred during an average of $36 \%$ of intervals (range $=25 \%-48 \%$ ).

During implementation of the TC, off-task $(M=28 \%$, range $=22 \%-34 \%)$, out-of-seat $(M=1 \%$, range $=0-3)$, and inappropriate vocalizations $(M=8 \%$, range $=4 \%-16 \%)$ all 


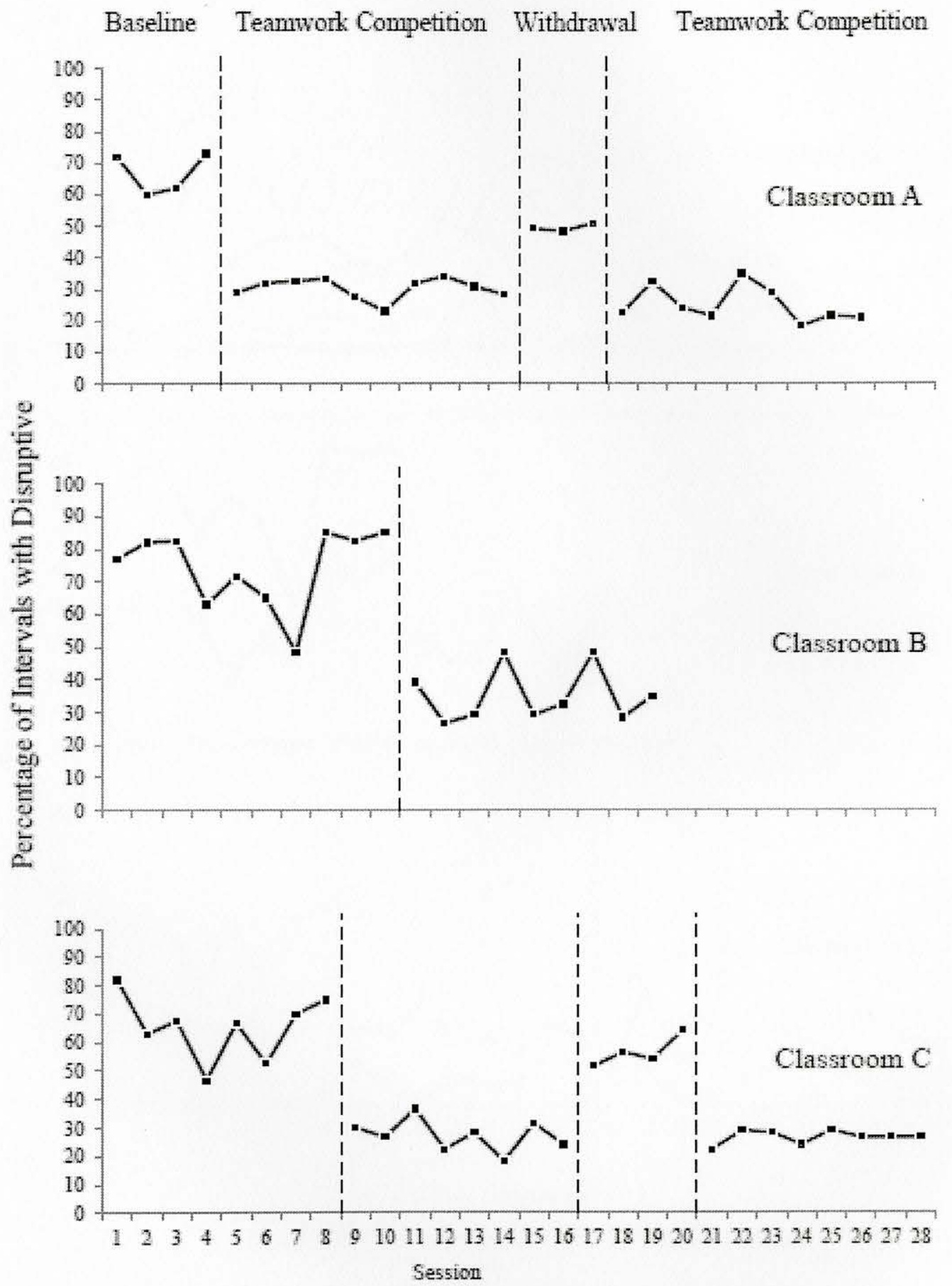

Figure 1. Disruptive Behavior Across Phases for Classrooms A, B, and C. 


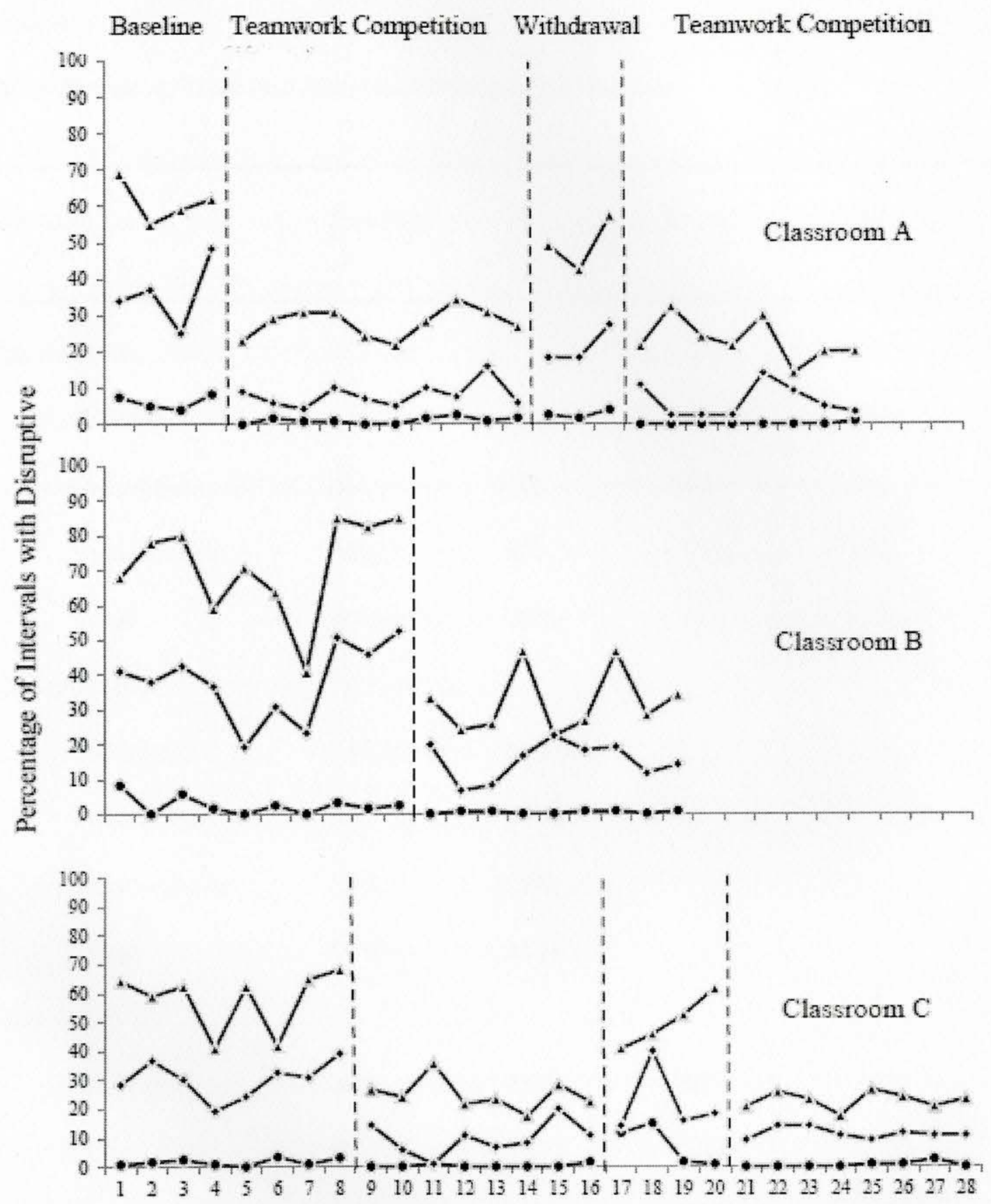

Session

---Off-Task -*-Out-of-Seat -+-Vocalizations

Figure 2. Off-Task, Out-of-Seat, and Inappropriate Vocalizations Across Phases for Classrooms A, B, and C. 
Table 1

Mean Percent of Total and Individual Disruptive Behaviors

Behavior

Baseline TC Withdrawal

TC

Classroom A:

$\begin{array}{llccc}\text { Off-task } & 61 \% & 28 \% & 50 \% & 23 \% \\ \text { Out-of-Seat } & 6 \% & 1 \% & 3 \% & 0 \% \\ \text { Vocalizations } & 36 \% & 8 \% & 21 \% & 6 \% \\ \text { Total } & \mathbf{6 7 \%} & \mathbf{3 0} \% & \mathbf{5 0} \% & \mathbf{2 6 \%}\end{array}$

Classroom B:

$\begin{array}{lll}\text { Off-task } & 71 \% & 32 \% \\ \text { Out-of-Seat } & 3 \% & 0.5 \% \\ \text { Vocalizations } & 38 \% & 15 \% \\ \text { Total } & \mathbf{7 4 \%} & \mathbf{3 5 \%}\end{array}$

Classroom C:

$\begin{array}{lllll}\text { Off-task } & 52 \% & 25 \% & 50 \% & 24 \% \\ \text { Out-of-Seat } & 2 \% & 0.5 \% & 7 \% & 0.5 \% \\ \text { Vocalizations } & 30 \% & 10 \% & 22 \% & 11 \% \\ \text { Total } & \mathbf{6 5 \%} & \mathbf{2 7 \%} & \mathbf{5 7 \%} & \mathbf{2 7 \%}\end{array}$

decreased immediately. During the withdrawal phase, off-task $(M=50 \%$, range $=42 \%$ $58 \%)$, out-of-seat $(M=3 \%$, range $=2-4)$, and inappropriate vocalizations $(M=21 \%$, range $=18 \%-28 \%$ ) all increased. Again, during the re-implementation phase, off-task 
$(\mathrm{M}=23 \%$, range $=22 \%-33 \%)$, out-of-seat $(M=0 \%$, range $=0-1)$, and inappropriate vocalizations $(\mathrm{M}=6 \%$, range $=3 \%-11 \%)$ all decreased.

During baseline, students in Classroom B (middle panel, Figure 1) displayed disruptive behaviors during an average of $74 \%$ of intervals (range $=48 \%-85 \%$ ), although there was considerable variability. There was an immediate reduction in targeted disruptive behavior following the implementation of the TC. The percentage of intervals in which students displayed disruptive behaviors decreased to an average of $35 \%$ (range $=28 \%-48 \%)$ during the TC phase. Additionally, during the TC phase, only two data points overlapped with the lowest datum point in baseline.

Individual behaviors were also tracked and graphed and can be seen in the middle panel of Figure 2. During baseline off-task behaviors occurred during an average of $71 \%$ of intervals (range $=59 \%-85 \%$ ), out-of-seat behavior occurred in an average of $3 \%$ of intervals (range $=0 \%-8 \%$ ), and inappropriate vocalizations occurred an average of $38 \%$ of intervals (range $=19 \%-52 \%)$. During implementation of the TC, off-task $(M=32 \%$, range $=24 \%-47 \%)$, out-of-seat $(M=0.5 \%$, range $=0-1)$, and inappropriate vocalizations $(M=15 \%$, range $=7 \%-19 \%)$ decreased immediately.

During baseline, students in Classroom C (bottom panel, Figure 1) displayed disruptive behaviors during an average of $65 \%$ of intervals (range $=47 \%-82 \%$ ) with considerable variability. There was an immediate reduction in targeted disruptive behavior following the implementation of the TC. The percentage of intervals in which students displayed disruptive behaviors decreased to an average of $27 \%$ of intervals (range $=18 \%-37 \%)$. To further increase experimental control a withdrawal phase occurred in which the intervention was removed from the classroom for a short time. During this phase the percentage of intervals containing disruptive behaviors increased to 
near baseline levels, occurring during an average of $57 \%$ of intervals (range $=52 \%$ 64\%). Following this phase the TC was re-implemented and again occurrence of disruptive behaviors decreased to an average of $27 \%$ (range $=23 \%-29 \%$ ) of intervals. There were no overlapping data points across intervention and non-intervention phases. Individual behaviors were tracked and graphed (bottom panel, Figure 2). For Classroom C, during baseline off-task behaviors occurred during in an average of $58 \%$ of intervals (range $=41 \%$ - 68\%), out-of-seat behavior occurred in an average of $2 \%$ of intervals (range $=1 \%-3 \%$ ), and inappropriate vocalizations occurred in an average of $30 \%$ of intervals $($ range $=19 \%-39 \%)$. During implementation, off-task $(M=25 \%$, range $=18 \%-28 \%)$, out-of-seat $(M=0.5 \%$, range $=0 \%-2 \%)$, and inappropriate vocalizations $(M=10 \%$, range $=1 \%-14 \%)$ all decreased immediately. Again, during the withdrawal phase, off task $(M=50 \%$, range $=41 \%-62 \%)$, out-of-seat $(M=7 \%$, range $=1 \%-15 \%)$, and inappropriate vocalizations $(M=22 \%$, range $=14 \%-40 \%)$ all increased. During the re-implementation phase, off task $(M=24 \%$, range $=21 \%-27 \%)$, out-of-seat $(M=$ $0.5 \%$, range $=0-3)$, and inappropriate vocalizations $(M=11 \%$, range $=9 \%-14 \%)$ all decreased.

\section{Teacher Acceptability}

Following data collection the teachers of each classroom completed the modified IRP-15. Ms. Adams (Teacher A) rated the GBG/TC as an 80, Mr. Boyd (Teacher B) responded with a rating of 63, and Mrs. Carmen (Teacher C) provided a rating of 75. Ms. Adams and Mr. Boyd did not agree that the intervention was consistent with ones they had used in the past. Mr. Boyd also slightly disagreed that the intervention was a fair or good way to handle the behavior problems present in his classroom. Otherwise, all three teachers agreed (to some extent) with all other statements on the IRP-15. Additionally, 
Both Ms. Adams and Mrs. Carmen noted that they were implementing the GBG/TC in class periods outside of those referred for inclusion in the study and noted they were pleased with the results in those other classrooms.

\section{Student Acceptability}

Following the final day of data collection the students were asked to complete the modified CIRP acceptability rating scale or read quietly at their seats. All students present on the day acceptability data were collected elected to complete the form. Again, reliability and validity have not been established for the CIRP; however, more agreement answers indicate higher acceptability. A point was assigned to each agreement by the student. Therefore the highest rating possible was an 8 (see Table 2).

On the day of acceptability data collection for Classroom A, 18 students were present and completed the modified CIRP form. The student's in Ms. Adams' class gave the TC an average rating of $5.94($ range $=0-8)$. The least acceptable item for Classroom A was item 8 . Further information provided by a few students noted that they did not think other students would like working as teams.

On the day of acceptability data collection for Classroom B, 20 students were present and completed the modified CIRP form. The student's in Mr. Boyd's class gave the TC an average rating of 4.65 (range $=0-8)$. The least acceptable items for Classroom B were items 3, 6, and 8. Several students further indicated that they felt Mr. Boyd was unfair in assigning marks and did not stick to the rules of the game, which was also noted by the observers during several sessions.

On the day of acceptability data collection for Classroom C, 19 students were present and completed the modified CIRP form. The student's in Mrs. Carmen's class 
Table 2

Percent of students who Endorsed items of Modified CIRP

Question

Classroom A

Classroom B

Classroom C

Did you like the TC?

$94 \%$

$70 \%$

$58 \%$

Did you like participating in the TC? 78\%

$80 \%$

$63 \%$

Other students?

$72 \%$

$40 \%$

$42 \%$

Rewards?

$78 \%$

$95 \%$

$89 \%$

Helped do better in class?

$83 \%$

$50 \%$

$63 \%$

Was it fair?

$78 \%$

$45 \%$

$47 \%$

Did not cause problems for you. $\quad 67 \%$

$55 \%$

$74 \%$

Did not cause problems for others. $\quad 44 \%$

$30 \%$

$47 \%$

gave the TC an average rating of 4.84 (range $=2-8)$. The least acceptable items for

Classroom C were items 3, 6, and 8. Several students noted that they did not think Mrs.

Carmen was fair in mark distribution or that they did not think students would enjoy working in teams. 


\section{CHAPTER IV}

\section{DISCUSSION}

Although the effectiveness of the Good Behavior Game (GBG)/Teamwork Competition (TC) on managing a variety of behaviors has been investigated across many developmental levels, not all populations have been adequately investigated. Studies have found the GBG to be effective across ages ranging from pre-school to adulthood. However, the present study is only one of two to utilize the procedure with a general education high school population (See also Kleinman \& Saigh, 2011). One reason for the smaller research base of implementation of the GBG/TC intervention in high school classrooms is that many (e.g., teachers, researchers) feel the procedure may not be developmentally appropriate. However, components of the GBG/TC are based on sound behavioral principles (i.e., differential reinforcement of low rates of behavior, clear expectations, feedback, and monitoring) which are not limited by age; therefore, the intervention may in fact be effective and developmentally appropriate for this age group.

\section{Research Questions}

\section{Research Question 1}

The results of the present study are consistent with those of Kleinman and Saigh (2011) indicating that a modified version of the GBG can be effectively employed with high school students. The data reflect clear and immediate decreases in disruptive behavior for all classrooms during intervention phases. As in previous literature, these data suggest that the GBG/TC can, in fact, effectively decrease the disruptive behavior of general education high school students, thereby affirming Research Question 1. 


\section{Research Question 2}

Additionally, the present study sought to examine the acceptability of the GBG/TC by the teachers implementing the intervention (Research Question 2). Although some teachers may have reservations about the use of a technique originally designed to target disruptive behaviors in elementary aged students, the basic principles of the game still serve to decrease the targeted behaviors of older students. However, because an intervention works or is feasible does not deem it acceptable or developmentally appropriate. Based on the results of a modified IRP-15, all three teachers felt that the GBG/TC was an overall acceptable intervention for use in their classrooms. Furthermore, two of the three teachers in the study noted that they employed the intervention in additional classes and reported satisfaction with those students' behavioral improvements.

\section{Research Question 3}

Research Question 3 sought to determine if the GBG/TC would be acceptable to the students. Based on the CIRP, students yielded mixed acceptability ratings, but found the intervention to be at least somewhat acceptable (Witt \& Elliott, 1985). Many of the students did not feel that the intervention was fair (i.e., they did not get to pick their teams or felt the teacher was biased) or that it caused problems for other students (i.e., negative consequences in place for target behaviors that were not previously present).

Furthermore, GBG/TC procedures focus on maintaining appropriate behavior and discouraging inappropriate behaviors at the class-wide level which are consistent with PBIS systems (Sugai et al., 2000). The present study found the GBG/TC to be not only an effective technique for managing classroom behavior at the high school level, but also an acceptable one as rated by participating teachers and students. Because there is such 
limited research on interventions and procedures to improve behavior that are effective and consistent with the PBIS system at the high school level, this study serves as evidence that the GBG/TC is a viable option for teachers at the high school level who are in need of additional support services for student behavior at the classwide level (Schanding \& Sterling-Turner, 2010; Kleinman \& Saigh, 2011)

\section{Limitations}

Although the present study supports the effectiveness and acceptability of the GBG with a general education high school population, some limitations should be noted. The study was conducted in a naturalistic setting, general education high school classrooms, and therefore there were many variables beyond the control of the study (i.e., variations in schedule, whole group/small group/independent desk work). Some variations in the school schedules included assemblies (e.g., pep rallies), picture day, college/job fairs, and field trips which may have impacted attendance or class period length. Though none of these variations were present during phase changes, these variations may have affected the stability of some data.

Another possible limitation of the study includes the use of tangible rewards. The most popular reward included tangibles (i.e., candy or pencils) which are of a low monetary value. It is important to note that though this cost was low for the purpose of the current study, over the course of months or with multiple classrooms, this could add up to a value that is not feasible or affordable to some teachers. Again, it is also important to note that though the primary investigator purchased all tangible rewards for the referred classrooms, Ms. Adams and Mrs. Carmen both elected to utilize the GBG/TC in other classrooms at their own expense and noted that they felt this was feasible for them. 
Additionally, several issues regarding Mr. Boyd and Classroom B should be discussed. Mr. Boyd was on a behavior improvement plan with the school administrators due to undesirable and inconsistent performance for both classroom management and lesson planning during prior administrative checks. Prior to baseline data collection, Mr. Boyd had received extensive training from school administrators regarding his lesson plans. During implementation, observers felt that Mr. Boyd struggled with implementation of the TC and did not seem to understand the spirit of the game, often taking the competition component out of the game by marking every instance of every student's disruptive behavior on one team and ignoring the other team completely. During some observations there was as much as a 30 point difference between the teams' scores. This drastic difference usually led to indifference for the losing team, and they ignored the game completely. Mr. Boyd also fell below $80 \%$ of procedural integrity during one of the observations and was retrained. Because integrity data were only collected when observers were present, and the intervention was inconsistent when observers were present, it is possible that the treatment integrity checklist may not have captured true integrity for Mr. Boyd's implementation of the GTC.

Furthermore, Classroom B did not receive a withdrawal/re-implementation phase. After approximately one month of implementation, Mr. Boyd decided that he would like to make changes to his classroom that would alter the experimental control of the study, and therefore he elected to withdrawal from the study, and his class was no longer monitored for behavioral changes. Mr. Boyd indicated that he planned to continue using some form of the intervention.

Some potential limitations to external validity are also worth noting. The amount of disruptive behaviors of the referred classrooms was high and a bit above what might 
be expected in typical high school classrooms. Therefore, it is not possible to say whether the game would be effective in reducing behaviors in classrooms with lower levels of disruptive behavior. Additionally, the majority of students were African-American and of low SES. Also, although the classes were composed of mixed grades, the majority of students in the three classrooms were ninth or tenth graders. Therefore, it is not certain whether the game would be effective with students of differing backgrounds, higher SES, or higher grades (i.e., all/mostly eleventh or twelfth graders).

\section{Future Research}

Though not monitored formally, both the observers and Ms. Adams noted that the amount of academic material she was able to cover and what her students were able to understand increased dramatically from baseline sessions to intervention sessions. Future researchers may wish to track academic behaviors (e.g., word completion, accuracy) and performance. Another area that may be worth investigating is the types of rewards in the game. Most students preferred the edible rewards (candy) to the free rewards (i.e., extra points, homework passes) they requested during the preference assessment. It would be interesting to see if limiting the amount of a certain reward (e.g., only getting candy once a week) would affect the results. Also, as previously noted the students utilized in the present study were of low SES. An area of further investigation may be to see whether these types of rewards or the GBG/TC in general, would be effective with students of higher SES who could purchase the tangibles on their own. That is, due to an abolishing operation of already having greater access to tangibles, other types of reinforcers or rewards may be necessary for the intervention to be effective with higher SES students. Though the reinforcers for this population may need to be altered, the structure of the game would still be intact and would not change, just the rewards. 
Additionally variations such as making criteria for rewards known to the students versus unknown or randomization of components in a general education high school classroom could be explored. It is also not known whether dividing the class into teams is necessary at the secondary level. If the GBG is effective without the team component, it might further streamline teachers' monitoring and record-keeping, and, thus, time involvement with the procedure.

\section{Implications}

The present study contributes to the current literature in a number a ways. Consistent with previous studies, this study serves as evidence that group contingencies are viable techniques for managing inappropriate behaviors in high school classrooms, and that the GBG/TC is a viable option to incorporate within a PBIS system at the secondary level. High school teachers, administrators, and school psychologists are often searching for appropriate Tier I and Tier II management procedures at the high school level. The present study demonstrates that the GBG/TC may serve as an effective procedure to use with high school students at either a Tier I or Tier II level.

In addition to demonstrating the effectiveness of the GBG/TC, the study also demonstrated that in addition to being an effective method for managing disruptive behavior, the GBG/TC is also deemed acceptable by high school teachers and students who participated in the study. Although there was some hesitation in using teams in a high school classroom, the results of the acceptability rating scales support the use of the GBG/TC by both teachers and students who participated. 


\section{APPENDIX A}

\section{TEACHER CONSENT FORM}

Dear Teacher,

I am a graduate student in the School Psychology Program at The University of Southern Mississippi working under the guidance of Dr. Daniel Tingstrom. As part of my thesis, I am researching the effectiveness of a classroom-based intervention, the Good Behavior Game (GBG), a procedure used to decrease disruptive behavior. Your classroom has been referred for class wide disruptive behavior, which the intervention aims to address, therefore we hope you will participate in the study.

If you agree to participate in this study, we will ask you to perform several tasks. First, prior to the implementation of the GBG, you will be asked to complete a consultation session with me to obtain information regarding your students' behavioral concerns. Following this consultation, a screening procedure will be conducted to verify your classroom's capacity for participation. If your classroom qualifies for participation, I will conduct a training session to explain and practice the steps of the intervention with you prior to implementation. The GBG is an intervention in which two teams compete to obtain the fewest amount of check marks for disruptive classroom behavior. Low numbers of disruptive behavior will enable students on the winning team to gain access to rewards.

In order to participate in the study, your classroom must demonstrate disruptive behavior in at least $30 \%$ of the observation intervals at the time of the screening session in order qualify for the study. If the classroom does not qualify for participation other services will be made available to you.

Throughout the study, classroom observations will be conducted multiple times a week by myself or another trained graduate student from the USM School Psychology program. The study will consist of two phases. Following the initial screening observation, data will be collected on the targeted disruptive behavior. At this time, you will conduct class as normal without the implementation of the GBG. During the second phase, the GBG will be implemented in the classroom. The game will consist of dividing the students into two teams and marking points against a team each time a team member performs and inappropriate behavior or breaks a classroom rule. At the end of each day the team with the least marks against them, or both teams if neither exceeds a pre-set criterion, will win the game and will earn access to an approved reinforcer.

Following each day of observations, you will be provided with feedback on the game implementation. At the end of the study, you and your students will be asked to complete a questionnaire to assess your satisfaction with the GBG.

Agreeing to participate in this study may offer several benefits for you and your students. By participating in this study you will be trained on the implementation of a new intervention technique that can be used with other students. An additional benefit is the expected decrease in inappropriate behaviors and the increased appropriate behaviors by your students.

Students' behavior will be monitored to ensure undesired effects (e.g., increase in inappropriate behaviors) do not happen. Should we observe any unanticipated effects on 
your students' behavior, modifications or discontinuation of the intervention will occur, and your students will be provided with other appropriate services. There appear to be very few risks for either you or your students participating in this study. The greatest discomfort for you may be related to implementing a new procedure in the classroom. To reduce discomfort, I and/or other trained graduate students will provide training, materials, and will be available to answer any questions you may have. Your students should not experience any discomfort from the implementation of the recommended intervention.

All interviews, observations, and other information obtained during this study will be kept strictly confidential. Your name, students' names, and other identifying information will not be disclosed to any person not connected with this study. Results from this research project may be shared at professional conferences or published in scholarly journals; however, all identifying information will be removed from publications and/or presentations. Your participation in this study is entirely voluntarily. In addition, you may withdraw from this study at any time without penalty, prejudice, or loss of benefits. Further services, if needed, may be provided outside the scope of this study. Whereas no assurance can be made concerning results that may be obtained (as results from investigational studies cannot be predicted) the researcher will take every precaution consistent with the best scientific practice.

If you agree to participate, please read, sign, and return the following page. Please keep this letter for your records. If you have any questions about this study, please contact Rachel R. Mitchell at (228.327.2005; Rachel.Mitchell@eagles.usm.edu) or Dr. Daniel Tingstrom (601.266.4594; Daniel.Tingstrom@usm.edu). This project and this consent form have been reviewed by the Human Subjects Protection Review Committee at USM, which ensures that research projects involving human subjects follow federal regulations. Any questions or concerns about rights as a research subject should be directed to the Institutional Review Board Office, The University of Southern Mississippi, Box 5147, Hattiesburg, MS 39406-5147, (601) 266-6820.

Sincerely,

Rachel R. Mitchell

School Psychologist in Training 


\section{THIS SECTION TO BE COMPLETED BY TEACHER}

Please Read and Sign the Following:

I have read the above documentation and consent to participate in this project. I have had the purpose and procedures of this study explained to me and have had the opportunity to ask questions. I am voluntarily signing this form to participate under the conditions stated. I have also received a copy of this consent. I understand that I will be asked to implement a classroom-based intervention called the Good Behavior Game, and observations will be conducted in the classroom on the students' behavior. In order to do so, I will be required to complete a consultation session, to implement the intervention, and to complete a structured questionnaire to assess my satisfaction with the intervention. In addition, I will be trained on all of the intervention procedures by the primary experimenter. I further understand that all data collected in this study will be confidential and that my name and the students' names will not be associated with any data collected. I understand that I may withdraw my consent for participation at any time without penalty, prejudice, or loss of privilege.

Signature of Teacher

Signature of Witness 


\section{APPENDIX B}

\section{TEACHER SCRIPT}

1) Introduction of the Teamwork Competition

- Inform students that there will now be a team competition each day during the set class period. At this time, students are expected to follow all of the classroom rules.

2) State and demonstrate class expectations

- Remind the class of each classroom rule. If the target behaviors are not a part of the classroom rules, those should also be explained. The teacher should demonstrate the expected appropriate behaviors for the class to see.

3) Explain Competition procedures and divide the class into teams

- Divide the students into two teams and write the names on the board. Explain the kinds of behaviors that will result in marks against teams. Teams will be informed of the reinforcers that will be awarded to winning teams and that both teams may be able to earn the rewards by staying under the set criterion.

4) Following the introduction to the class, the Teamwork Competition will immediately begin

- Disruptive behaviors and those that go against the classroom rules will immediately begin earning marks for teams.

5) End the competition and award the winning team(s)

- At the end of the game each day the points will be tallied and the winner(s) announced 


\section{APPENDIX C}

\section{TEACHER ACCEPTABILITY RATING SCALE}

\section{Intervention Rating Profile-15 (IRP-15)/Modified Version}

Please respond to each of the following statements thinking about the intervention implemented. Please then circle the number associated with your response. Be sure to answer all statements.

\begin{tabular}{|c|c|c|c|c|c|c|}
\hline & $\begin{array}{l}\text { Strongly } \\
\text { Disagree }\end{array}$ & Disagree & $\begin{array}{l}\text { Slightly } \\
\text { Disagree }\end{array}$ & $\begin{array}{l}\text { Slightly } \\
\text { Agree }\end{array}$ & Agree & $\begin{array}{l}\text { Strongly } \\
\text { Agree }\end{array}$ \\
\hline $\begin{array}{l}\text { This was an acceptable intervention for } \\
\text { the problem behavior(s). }\end{array}$ & $\overline{1}$ & 2 & 3 & 4 & 5 & 6 \\
\hline $\begin{array}{l}\text { Most teachers would find this } \\
\text { intervention appropriate for behavior } \\
\text { problems in addition to the ones } \\
\text { described. }\end{array}$ & 1 & 2 & 3 & 4 & 5 & 6 \\
\hline $\begin{array}{l}\text { This intervention proved effective in } \\
\text { helping to change the problem } \\
\text { behavior(s) of the classroom. }\end{array}$ & 1 & 2 & 3 & 4 & 5 & 6 \\
\hline $\begin{array}{l}\text { I would suggest the use of this } \\
\text { intervention to other teachers. }\end{array}$ & 1 & 2 & 3 & 4 & 5 & 6 \\
\hline $\begin{array}{l}\text { The classroom behavior problem was } \\
\text { severe enough to warrant the use of this } \\
\text { intervention. }\end{array}$ & 1 & 2 & 3 & 4 & 5 & 6 \\
\hline $\begin{array}{l}\text { Most teachers would find this } \\
\text { procedure suitable for the problem } \\
\text { behavior(s) described. }\end{array}$ & 1 & 2 & 3 & 4 & 5 & 6 \\
\hline $\begin{array}{l}\text { I would be willing to use the } \\
\text { intervention again in the classroom } \\
\text { setting. }\end{array}$ & 1 & 2 & 3 & 4 & 5 & 6 \\
\hline $\begin{array}{l}\text { The intervention did not result in } \\
\text { negative side effects for the students. }\end{array}$ & 1 & 2 & 3 & 4 & 5 & 6 \\
\hline $\begin{array}{l}\text { This intervention would be appropriate } \\
\text { for a variety of students. }\end{array}$ & 1 & 2 & 3 & 4 & 5 & 6 \\
\hline $\begin{array}{l}\text { This intervention was consistent with } \\
\text { those I have used in the classroom } \\
\text { setting before. }\end{array}$ & 1 & 2 & 3 & 4 & 5 & 6 \\
\hline $\begin{array}{l}\text { This intervention was a fair way to } \\
\text { handle problem behavior in the } \\
\text { classroom. }\end{array}$ & 1 & 2 & 3 & 4 & 5 & 6 \\
\hline $\begin{array}{l}\text { This intervention was reasonable for } \\
\text { the problem behavior(s) described. }\end{array}$ & 1 & 2 & 3 & 4 & 5 & 6 \\
\hline $\begin{array}{l}\text { I liked the procedures used in this } \\
\text { intervention. }\end{array}$ & 1 & 2 & 3 & 4 & 5 & 6 \\
\hline $\begin{array}{l}\text { The intervention was a good way to } \\
\text { handle the behavior problem(s). }\end{array}$ & 1 & 2 & 3 & 4 & 5 & 6 \\
\hline $\begin{array}{l}\text { Overall, this intervention was } \\
\text { beneficial. }\end{array}$ & 1 & 2 & 3 & 4 & 5 & 6 \\
\hline
\end{tabular}

Taken and adapted from, Martens, B. K., Witt, J. C., Elliottt, S. N. \& Darveaux, D. (1985). Teacher judgments concerning the acceptability of school-based interventions. Professional Psychology: Research and Practice, 16, 191-198 


\section{APPENDIX D}

\section{STUDENTS ACCEPTABILITY RATING SCALE}

\section{Student's Intervention Rating Profile/Modified Version}

1. Did you like the Teamwork Competition used in your classroom?

- Yes No

2. Did you like participating in the Teamwork Competition?

- Yes No

3. Do you think other students would like to use the Teamwork Competition?

- Y Yes No

4. Did you like the rewards earned during the Teamwork Competition?

- Yes No

5. Do you think the Teamwork Competition has helped you do better in (class name)?

- _ Yes No

6. Do you think the Teamwork Competition was fair?

- Y Yes No

7. Do you think the Teamwork Competition caused any problems for you? Yes No

8. Do you think the Teamwork Competition caused any problems for your classmates?

No

Please explain any questions to which you answered "No":

Adapted from Witt, J. C., \& Elliottt, S. N. (1985). Acceptability of classroom intervention strategies. In T. R. Kratochwill (Ed.), Advances in School Psychology (Vol. 4, pp. 251-288). Hillsdale, NJ: Erlbaum. Copyright 1985 by Lawrence Erlbaum Associates, Inc. Reprinted. 


\section{APPENDIX E}

\section{OBSERVATION SHEET}

Teacher name:

Date:

Observer name:

\begin{tabular}{|c|c|c|c|c|c|c|c|}
\hline Interval & Off-Task & Out-of-Seat & In. Vocs. & Interval & Off-Task & Out-of-Seat & In. Vocs. \\
\hline 1.1 & & & & 11.1 & & & \\
\hline 1.2 & & & & 11.2 & & & \\
\hline 1.3 & & & & 11.3 & & & \\
\hline 1.4 & & & & 11.4 & & & \\
\hline 1.5 & & & & 11.5 & & & \\
\hline 1.6 & & & & 11.6 & & & \\
\hline 2.1 & & & & 12.1 & & & \\
\hline 2.2 & & & & 12.2 & & & \\
\hline 2.3 & & & & 12.3 & & & \\
\hline 2.4 & & & & 12.4 & & & \\
\hline 2.5 & & & & 12.5 & & & \\
\hline 2.6 & & & & 12.6 & & & \\
\hline 3.1 & & & & 13.1 & & & \\
\hline 3.2 & & & & 13.2 & & & \\
\hline 3.3 & & & & 13.3 & & & \\
\hline 3.4 & & & & 13.4 & & & \\
\hline 3.5 & & & & 13.5 & & & \\
\hline 3.6 & & & & 13.6 & & & \\
\hline 4.1 & & & & 14.1 & & & \\
\hline 4.2 & & & & 14.2 & & & \\
\hline 4.3 & & & & 14.3 & & & \\
\hline 4.4 & & & & 14.4 & & & \\
\hline 4.5 & & & & 14.5 & & & \\
\hline 4.6 & & & & 14.6 & & & \\
\hline 5.1 & & & & 15.1 & & & \\
\hline 5.2 & & & & 15.2 & & & \\
\hline 5.3 & & & & 15.3 & & & \\
\hline 5.4 & & & & 15.4 & & & \\
\hline 5.5 & & & & 15.5 & & & \\
\hline 5.6 & & & & 15.6 & & & \\
\hline 6.1 & & & & 16.1 & & & \\
\hline 6.2 & & & & 16.2 & & & \\
\hline 6.3 & & & & 16.3 & & & \\
\hline 6.4 & & & & 16.4 & & & \\
\hline 6.5 & & & & 16.5 & & & \\
\hline 6.6 & & & & 16.6 & & & \\
\hline 7.1 & & & & 17.1 & & & \\
\hline 7.2 & & & & 17.2 & & & \\
\hline 7.3 & & & & 17.3 & & & \\
\hline 7.4 & & & & 17.4 & & & \\
\hline 7.5 & & & & 17.5 & & & \\
\hline 7.6 & & & & 17.6 & & & \\
\hline 8.1 & & & & 18.1 & & & \\
\hline 8.2 & & & & 18.2 & & & \\
\hline 8.3 & & & & 18.3 & & & \\
\hline 8.4 & & & & 18.4 & & & \\
\hline 8.5 & & & & 18.5 & & & \\
\hline 8.6 & & & & 18.6 & & & \\
\hline 9.1 & & & & 19.1 & & & \\
\hline 9.2 & & & & 19.2 & & & \\
\hline 9.3 & & & & 19.3 & & & \\
\hline 9.4 & & & & 19.4 & & & \\
\hline 9.5 & & & & 19.5 & & & \\
\hline 9.6 & & & & 19.6 & & & \\
\hline 10.1 & & & & 20.1 & & & \\
\hline 10.2 & & & & 20.2 & & & \\
\hline 10.3 & & & & 20.3 & & & \\
\hline 10.4 & & & & 20.4 & & & \\
\hline 10.5 & & & & 20.5 & & & \\
\hline 10.6 & & & & 20.6 & & & \\
\hline
\end{tabular}

Off-task behavior: the student's attention (eyes/face) directed away from the assignment or instructing teacher for more than 3 seconds; this may include a student looking at another student, having his/her eyes closed, rummaging through his/her book bag at inappropriate times, or staring/spacing out. Out-of-seat: the student's buttocks breaking contact with his/her seat for more than 3 seconds without teacher permission.

Inappropriate vocalizations: voluntary audible verbalization made without

Occurrence of OT= Occurrence of $\mathrm{OOS}=$ Occurrence of IV= TOTAL Intervals=
$/ 120=$

$1120=\%$

$/ 120=\%$ $-1120=\quad \%$ 


\section{APPENDIX F}

\section{BASELINE/WITHDRAWAL INTEGRITY CHECKLIST}

Teacher Name:

Date:

Observer:

\begin{tabular}{|l|l|}
\hline Training Steps & $\checkmark$ \\
\hline Class not divided into teams & \\
\hline Teams not mentioned & \\
\hline Rewards not mentioned & \\
\hline Rewards not given & \\
\hline Steps Completed & \\
\hline Steps Possible & \\
\hline
\end{tabular}

Percentage of steps completed: 
APPENDIX G

PROCEDURAL INTEGRITY CHECKLIST

Teacher Name:

Date:

Observer:

*PP=Permanent Product

\begin{tabular}{|l|l|l|}
\hline Training Steps & Yes & No \\
\hline 1. Teacher announces/reminds students of the game/rules & & \\
\hline 2. Rules are displayed so that students can see them (PP) & & \\
\hline 3. Students are divided into teams (visual inspection) (PP) & & \\
\hline 4. Team names are displayed on board where they can be seen by students (PP) & & \\
\hline 5. Teacher reminds students of the daily criterion for both teams to win (PP) & & \\
\hline 6. Teacher identifies/records disruptive behavior as marks on the \\
board against teams (PP) & & \\
\hline 7. Teacher announces when the game is over & & \\
\hline 8. Teacher announces winning team(s) & & \\
\hline 9. Teacher allows winning team to access reward & & \\
\hline Steps Completed & & \\
\hline Steps Possible & & \\
\hline
\end{tabular}

*PP=Permanent Product

Percentage of steps completed:

Teacher requires retraining: Yes No

*Taken and adapted from, Hunt, B. M. (2010). The good behavior game with a preschool population (Unpublished master's thesis). The University of Southern Mississippi, Hattiesburg, MS. 


\section{APPENDIX H}

\section{STUDENT PREFERENCE ASSESSMENT}

In the space below, please list at least three rewards you would like to earn from (teacher name) in (class name) that would make you work harder and behave better in class. List as many things as you would be willing to "work" to earn (for example free time, extra points on a test, candy, pencils, etc.).

1)

2)

3)

Other: 


\title{
APPENDIX I
}

INSTITUTIONAL REVIEW BOARD APPROVAL LETTER

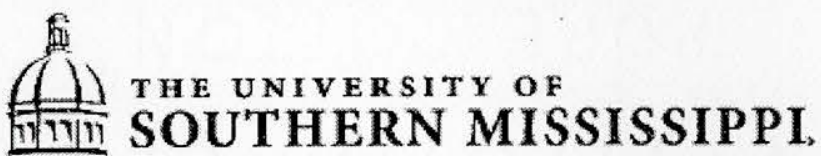

INSTITUTIONAL REVIEW BOARD

118 College Drive $\$ 5147$ | Hattiesbung, MS 39406-0001

Phone: 601.266 .6820 ) Fax: 601.266.4377 | www.usm.edu/2ts

\section{NOTICE OF COMMITTEE ACTION}

The project has been reviewed by The University of Southern Mississippi Institutional Review Board in accordance with Federal Drug Administration regulations (21 CFR 26, 111), Department of Health and Human Services (45 CFR Part 46), and university guidelines to ensure adherence to the following criteria:

- The risks to subjects are minimized.

- The risks to subjects are reasonable in relation to the anticipated benefits.

- The selection of subjects is equitable.

- Informed consent is adequate and appropriately documented.

- Where appropriate, the research plan makes adequate provisions for monitoring the data collected to ensure the safety of the subjects.

- Where appropriate, there are adequate provisions to protect the privacy of subjects and to maintain the confidentiality of all data.

- Appropriate additional safeguards have been included to protect vulnerable subjects.

- Any unanticipated, serious, or continuing problems encountered regarding risks to subjects must be reported immediately, but not later than 10 days following the event. This should be reported to the IRB Office via the "Adverse Effect Report Form".

- If approved, the maximum period of approval is limited to twelve months. Projects that exceed this period must submit an application for renewal or continuation.

\author{
PROTOCOL NUMBER: 11082905 \\ PROJECT TITLE: The Effects of the Good Behavior Game with \\ General Education High School Students \\ PROJECT TYPE: Dissertation \\ RESEARCHER/S: Rachel R. Mitchell \\ COLLEGEIDIVISION: College of Education \& Psychology \\ DEPARTMENT: Psychology \\ FUNDING AGENCY: NIA \\ IRB COMMITTEE ACTION: Expedited Review Approval \\ PERIOD OF PROJECT APPROVAL: 08/30/2011 to 08/29/2012
}

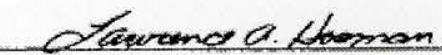

Lawrence A. Hosman, Ph.D.

$8-31-2011$

Institutional Review Board Chair

Date 


\section{REFERENCES}

Barrish, H. H., Saunders, M., \& Wolf, M. W. (1969). Good Behavior Game: Effects of individual contingencies for group consequences on disruptive behavior in the classroom. Journal of Applied Behavior Analysis, 2, 119-124.

Bostow, D., \& Geiger, O. G. (1976). Good behavior game: A replication and systematic analysis with a second grade class. School Applications of Learning Theory, 8 , $18-27$.

Christ, T. J. \& Christ, J. A. (2006). Application of an interdependent group contingency mediated by an automated feedback device: An intervention across three high school classrooms. School Psychology Review, 35, 78-90.

Darch, C. B. \& Thorpe, H. W. (1977). The principal game: A group consequence procedure to increase classroom on-task behavior. Psychology in the Schools, 14, 341-347.

Darveaux, D. X. (1984). The good behavior game plus merit: Controlling disruptive behavior and improving student motivation. School Psychology Review, 13, $510-514$

Davies, S. \& White, R. (2000). Self-management and peer-monitoring within a group contingency to decrease uncontrolled verbalizations of children with attentiondeficit/hyperactivity disorder. Psychology in the Schools, 37, 135-147.

Durmuscelebi, M. (2010). Investigating students misbehavior in classroom management in state and private primary schools with a comparative approach. Education, 130, 377- 383 .

Embry, D. D. (2002). The good behavior game: A best practice candidate as a universal behavioral vaccine. Clinical Child and Family Psychology Review, 5, 273-297. 
Fishbein, J. E. \& Wasik, B. H. (1981). Effect of the good behavior game on disruptive library behavior. Journal of Applied Behavior Analysis, 14, 89-93.

Franklin, C., Haris, M. B., \& Allen-Meares, P. (Eds.). (2006). The school services sourcebook: A guide for school-based professionals. New York, NY: Oxford University Press.

Freer P., \& Watson, T. S. (1999). A comparison of parent and teacher acceptability ratings of behavioral and conjoint behavioral consultation. School Psychology Review, 28, 672.

Gresham, F. M., \& Gresham, G. N. (1982). Interdependent, dependent, and independent group contingencies for controlling disruptive behavior. Journal of Special Education, 16, 101-110.

Hegerle, D. R., Kesecker, M. P., \& Couch, J. V. (1979). A behavior game for the reduction of inappropriate classroom behaviors. School Psychology Digest, 8, $339-343$.

Hunt, B. M. (2010). The good behavior game with a preschool population (Unpublished master's thesis). The University of Southern Mississippi, Hattiesburg, Mississippi.

Johnson, M. R., Turner, P. F., \& Konarski, E. A. (1978). The "good behavior game": A systematic replication in two unruly transition classrooms. Education and Treatment of Children, 1, 25-33.

Kleinman, K. E., \& Saigh, P. A. (2011). The effects of the good behavior game on the conduct of regular education New York City high school students. Behavior Modification, 35, 95-105. 
Litow, L., \& Pumroy, D. K. (1975). A brief review of classroom group-oriented contingencies. Journal of Applied Behavior Analysis, 8, 341-347.

Lutzker, J. R., \& White-Blackburn, G. (1979). The good productivity game: Increasing work performance in a rehabilitation setting. Journal of Applied Behavior Analysis, 12, 488.

Maloney, K. B., \& Hopkins, B. L. (1973). The modification of sentence structure and its relationship to subjective judgments of creativity in writing. Journal of Applied Behavior Analysis, 6, 425-433.

Martens, B. K., Witt, J. C., Elliottt, S. N., \& Darveaux, D. (1985). Teacher judgments concerning the acceptability of school-based interventions. Professional Psychology: Research and Practice, 16, 191-198.

McCurdy, B. L., Lannie, A. L., \& Bardabas, E. (2009). Reducing disruptive behavior in an urban school cafeteria: An extension of the good behavior game. Journal of School Psychology, 47, 39-54.

Medland, M. B. \& Stachnik, T. J. (1972). Good-behavior game: A replication and systematic analysis. Journal of Applied Behavior Analysis, 5, 45-51.

Mudgal, D. (2004). Good classwork game: Efficacy of an interdependent group contingency on mathematics seatwork. (Unpublished master's thesis). The University of Southern Mississippi, Hattiesburg, Mississippi.

Mudgal, D. (2006). Randomizing criteria within an interdependent group contingency: Effects on math seatwork. Dissertation Abstracts International: Section B: The Sciences and Engineering, 68, 1915.

Oldfather, P. (1993). What students say about motivating experience in a whole language classroom. The Reading Teacher, 46, 672-681 
Patrick, C. A., Ward, P., \& Crouch, D. W. (1998). Effects of holding students accountable for social behaviors during volleyball games in elementary physical education. Journal of Teaching in Physical Education, 17, 143-156.

Robertshaw, C. S., \& Hiebert, H. D. (1973). The astronaut game: A group contingency applied to a first grade classroom. School Applications of Learning Theory, 6, 28-33.

Saigh, P. A. \& Umar, A. M. (1983). The effects of a good behavior game on the disruptive behavior of Sudanese elementary school students. Journal of Applied Behavior Analysis, 16, 339-344.

Schanding, G. T., \& Sterling-Turner, H. E. (2010). Use of the mystery motivator for a high school class. Journal of Applied School Psychology, 1, 38-53.

Shaw, R., \& Simms, T. (2009). Reducing attention-maintained behavior through the use of positive punishment, differential reinforcement of low rates, and response marking. Behavioral Interventions, 24, 249-263.

Sugai, G., Horner, R. H., Dunlap, G., Hieneman, M., Lewis, T. J., Nelson, C. M., Scott, T., Liaupsin, C., Sailor, W., Turnbull, A. P., Turnbull III, H. R., Wickham, D., Wilcox, B. Ruef, M. (2000). Applying positive behavioral assessment in schools. Journal of Positive Behavior Interventions, 2, 131-143.

Sugai, G., \& Horner, R. H. (2002). Introduction to the special series on positive behavior support in schools. Journal of Emotional and Behavioral Disorders, 10, $130-135$.

Sugai, G., Lewis-Palmer, T., Todd, A., \& Horner, R. (2005). School-wide Evaluation Tool (version 2.1). Educational and Community Supports, University of Oregon. 
Swain, J. J., Allard, G. B., \& Holborn, S. W. (1982). The good toothbrushing game: A school-based dental hygiene program for increasing the toothbrushing effectiveness of children. Journal of Applied Behavior Analysis, 15, 171-176.

Swiezy, N. B., Matson, J. L., \& Box, P. (1992). The good behavior game: A token reinforcement system for preschoolers. Child and Family Behavior Therapy, 14, 21-32.

Theodore, L., Bray, M., Kehle, T., \& Dioguardi, R. (2004)._Contemporary review of group-oriented contingencies for disruptive behavior. Journal of Applied School Psychology, 20, 79-101.

Tillery, A. D., Varjas, K., Meyers, J., \& Collins, A. S. (2010). General education teachers' perceptions of behavior management and intervention strategies. Journal of Positive Behavior Interventions, 12, 86-102.

Tingstrom, D. H., Sterling-Turner, H. E., \& Wilczynski, S. M. (2006). The good behavior game: 1969-2002. Behavior Modification, 30, 225-253.

Von Brock, M. B., \& Elliottt, S. N. (1987). Influence of treatment effectiveness information on the acceptability of classroom interventions. Journal of School Psychology, 25, 131-144.

Westling, D. L. (2010). Teachers and challenging behavior: knowledge, views, and practices. Remedial \& Special Education, 31, 48-63.

Winbinger, B., Katsiyannis, A., \& Archwamety, T. (2000). Disciplinary practices in Nebraska's public schools. Journal of Child and Family Studies, 9, 389-399.

Witt, J. C., \& Elliott, S. N. (1985). Acceptability of classroom intervention strategies. In T.R. Krotochwill (Ed.), Advances in School Psychology, 4, 251-288. 